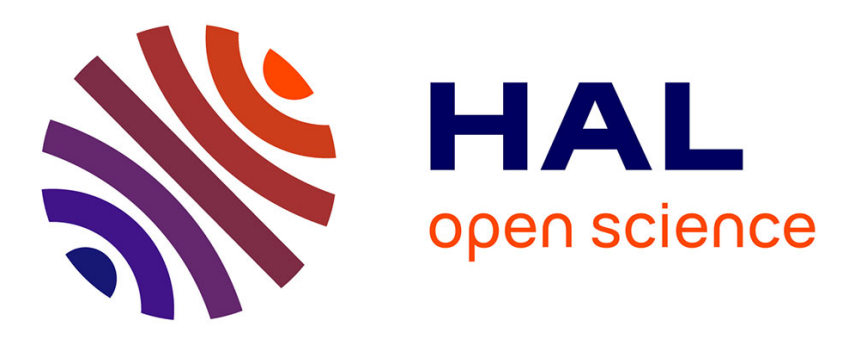

\title{
Rheological Controls on Asperity Weakening During Earthquake Slip
}

Kathryn S. Hayward, Rhys Hawkins, Stephen F. Cox, Charles Le Losq

\section{To cite this version:}

Kathryn S. Hayward, Rhys Hawkins, Stephen F. Cox, Charles Le Losq. Rheological Controls on Asperity Weakening During Earthquake Slip. Journal of Geophysical Research: Solid Earth, 2019, 124, pp.12,736-12,762. 10.1029/2019JB018231 . insu-03586589

\section{HAL Id: insu-03586589 \\ https://hal-insu.archives-ouvertes.fr/insu-03586589}

Submitted on 24 Feb 2022

HAL is a multi-disciplinary open access archive for the deposit and dissemination of scientific research documents, whether they are published or not. The documents may come from teaching and research institutions in France or abroad, or from public or private research centers.
L'archive ouverte pluridisciplinaire HAL, est destinée au dépôt et à la diffusion de documents scientifiques de niveau recherche, publiés ou non, émanant des établissements d'enseignement et de recherche français ou étrangers, des laboratoires publics ou privés.

$$
\text { Copyright }
$$




\author{
RESEARCH ARTICLE \\ 10.1029/2019JB018231 \\ Key Points: \\ - A microstructural evolution of \\ asperity interactions is documented \\ from the onset of flash heating to the \\ formation of sheared melt \\ - High strain rates and long relaxation \\ times cause melted asperity tips to \\ behave as glassy solids \\ - Melt rheology is essential for \\ understanding asperity behavior \\ and strength during the early stages \\ of earthquake slip
}

Correspondence to:

K. S. Hayward,

kathryn.hayward@anu.edu.au

Citation:

Hayward, K. S., Hawkins, R., Cox, S. F., \& Le Losq, C. (2019). Rheological controls on asperity weakening during earthquake slip. Journal of Geophysical Research: Solid Earth, 124,12,736-12,762. https://doi.org/10.1029/2019JB018231

Received 18 JUN 2019

Accepted 6 DEC 2019

Accepted article online 9 DEC 2019

Published online 19 DEC 2019

(C)2019. American Geophysical Union. All Rights Reserved.

\section{Rheological Controls on Asperity Weakening During Earthquake Slip}

\author{
Kathryn S. Hayward ${ }^{1}$, Rhys Hawkins ${ }^{2}$, Stephen F. Cox ${ }^{1}$, and Charles Le Losq ${ }^{1,3}$ \\ ${ }^{1}$ Research School of Earth Sciences, Australian National University, Canberra, ACT, Australia, ${ }^{2}$ Department of Earth \\ Sciences, Utrecht University, Utrecht, Netherlands, ${ }^{3}$ Laboratoire Géomatériaux, Institut de Physique du Globe de Paris, \\ Université de Paris, Paris, France
}

\begin{abstract}
Evolution of fault strength during the initial stages of seismic slip plays an important role in the onset of velocity-induced weakening, which in turn, leads to larger earthquake events. A key dynamic weakening mechanism during the early stages of slip is flash heating, where stress concentrations at contacts on the interface lead to the rapid generation of heat. Although potential weakening from flash heating has been extensively modeled, there is little recorded microstructural evidence of its physical manifestations. We present results of a series of triaxial experiments on synthetic faults in quartz sandstone. Samples were subjected to a variety of normal stresses and ambient temperatures, to induce a range of slip event sizes and sliding velocities. We show the microstructural evolution of asperity interactions from the onset of flash heating through to the formation of grain-scale areas of sheared melt. Using microstructural observations and mechanical data from the experiments, we model temperature and the viscoelastic behavior of the glass. Results suggest that, in the earliest stages of slip asperity contacts melt, but temperatures remain too low for viscous shear to occur within the melt layer. Instead melted asperities behave as glassy solids, facilitating continued frictional heating. With further slip, increased asperity temperatures allow the transition to viscous shear within the melt layer, facilitating weakening. These results highlight the dynamic evolution of the viscoelastic properties of the melt and resulting effects on asperity strength. Such complexity has, to-date, not been fully addressed in modeling of flash heating.
\end{abstract}

\section{Introduction}

Earthquake-producing rupture is thought to initiate from a small, highly stressed area of the fault interface (Aki, 1984; Johnston et al., 2006; Lay \& Kanamori, 1981). At earthquake nucleation, motion begins as either creep at the stressed contact or by fracture propagation through healed segments of a fault. In either case, once fault slip commences, large stress concentrations combined with the velocity of slip, produces heat and changes the mechanical properties of the interface (Niemeijer et al., 2012). Generally, the mechanical change is a weakening of the interface which, in turn, facilitates rupture propagation and further reduces fault strength (Sleep, 2019), allowing ruptures to become large and attain seismic slip velocities ( $v_{\text {slip }}>0.1 \mathrm{~m} / \mathrm{s}$; Sibson, 2002).

Reduction of the coefficient of sliding friction as a function of increasing slip velocity is referred to as dynamic weakening. This phenomenon occurs when frictional values decrease significantly from typical laboratory-derived, low velocity $(v<\mathrm{mm} / \mathrm{s})$ sliding friction estimates between 0.6 and 0.85 (Byerlee, 1978). Observations from large earthquake ruptures support the idea that various dynamic weakening mechanisms can play an important role in physical processes enabling the development of earthquakes. These include the following: (1) Unusually large stress drops and coseismic fault displacements relative to the estimated rupture area are associated with some earthquakes (Fujiwara et al., 2011; Malagnini et al., 2010; Rodgers \& Little, 2006), (2) absence of a heat flow anomaly that should accompany large ruptures in active fault zones, if higher frictional values are maintained (e.g., San Andreas fault, Brune et al., 1969; Lachenbruch \& Sass, 1980), and (3) the high seismic radiation efficiency of some earthquakes (Venkataraman \& Kanamori, 2004).

Laboratory experiments undertaken in a triaxial apparatus at normal stresses equivalent to those estimated for upper- to middle-crustal conditions are comparable to a small-scale version of the highly stressed fault nucleation zone (Brace \& Byerlee, 1966). The small displacements that can be achieved using these 
experiments are ideal for studying the initiation of slip and the critical first stages of dynamic weakening. For clarity, in this paper we refer to nanometer to micron-scale fault contacts as "asperities," even though the broader seismological definition of the word asperities refers to both the unevenness of a surface over a range of scales (geometric asperity) and multiscale differences in rheological properties (rheological asperity) leading to spatial variations in fault strength (Sagy \& Brodsky, 2009).

Studying the initial stages of slip is important for understanding the physical mechanism(s) by which dynamic weakening occurs. Possible mechanisms for dynamic weakening have been explored both experimentally and numerically, especially with the development of different high-velocity friction apparatus (e.g., Di Toro et al., 2010; Shimamoto \& Tsutsumi, 1994; Spray, 1987; see Ma et al., 2014 for review of apparatus). Mechanisms such as thermal pressurization (Lachenbruch, 1980; Mase \& Smith, 1987; Rempel \& Rice, 2006; Sibson, 1973; Wibberley \& Shimamoto, 2005), lubrication by silica gel or hydrated amorphous silica (Di Toro et al., 2004; Goldsby \& Tullis, 2002; Hayashi \& Tsutsumi, 2010; Nakamura et al., 2012; Rowe et al., 2019), dynamic activation/powder lubrication by gouge particles (Han et al., 2010; Reches \& Lockner, 2010; Siman-Tov et al., 2013), flash heating (Goldsby \& Tullis, 2011; Proctor et al., 2014; Rice, 2006), elastohydrodynamic lubrication (Brodsky \& Kanamori, 2001), thermal decomposition (Han et al., 2007), and lubrication by frictional melting (Di Toro et al., 2006; Fialko \& Khazan, 2005; Hirose \& Shimamoto, 2005; McKenzie \& Brune, 1972) have been proposed to produce significant dynamic weakening with dynamic friction values approaching 0.1 .

In this paper we focus on flash heating, which is the primary mechanism proposed for weakening during the onset of slip (first 1-2 mm). Flash heating was introduced to the fault mechanics community by Rice (1999) and used to describe highly localized frictional heating of stressed asperity contacts, resulting in thermally induced changes to the frictional properties of the asperities. Highly localized frictional heating occurs because fault surfaces are in contact over only a small fraction of their total area, concentrating the macroscopic force onto relatively small areas (Dieterich \& Kilgore, 1994; Logan \& Teufel, 1986). At slow slip rates generated during stable sliding, slip velocity is equivalent to loading rates (i.e., in experiments, generally in the order of microns per second) and the heat generated at the contact points diffuses into the adjacent wall rock, resulting in a small temperature rise and negligible effect on the contact's strength. With increasing slip rates accompanying the onset of stick-slip, time is insufficient for heat diffusion, resulting in increased temperatures, and potentially, melting of asperity contacts. If this occurs, the shear strength of the contact can transition from frictional sliding to being governed by the viscous properties of the melt (Chen \& Rempel, 2014; Rempel \& Weaver, 2008), although many classic models assume that the weakened state has no shear strength (Rice, 1999, 2006).

Laboratory specimens are commonly inferred to have asperity contact sizes between $\sim 1$ and $25 \mu \mathrm{m}$, based on extrapolation of direct observations made at low normal stresses $\left(\sigma_{N}<20 \mathrm{MPa}\right.$; Dieterich \& Kilgore, 1994) and assuming a purely elastic asperity model (Greenwood \& Williamson, 1966; Harbord et al., 2017; Nielsen et al., 2010). However, these assumptions have never been rigorously tested using microstructural analysis of asperity contacts on interfaces that have slipped at high normal stresses $\left(\sigma_{N}>\right.$ $100 \mathrm{MPa}$ ). Further, many earlier studies that explored flash heating and the early stages of slip initiation present only limited microstructural analysis, with observations generally being restricted to the identification of quenched melt on the fault surfaces (Brown \& Fialko, 2012; Harbord et al., 2017; Lockner et al., 2017; Passelégue et al., 2016), although Aubry et al. (2018) additionally used a novel technique to estimate asperity temperatures in situ, finding localized temperatures in excess of $1500{ }^{\circ} \mathrm{C}$. One of first studies to document the microstructural transition from flash heating to frictional melting that could be linked to slip behavior (velocity and displacement) was by Hayward et al. (2016). However, further microstructural work is needed to understand the nature of asperities and their interactions on fault surfaces.

To understand the behavior and microstructures of asperity contacts during the first tens to hundreds of microns of slip, experiments were performed over a range of pressure and temperature conditions using a Paterson triaxial deformation apparatus. Experimental materials were then analyzed by electron microscopy to examine structures formed during slip. Mechanical data and microstructural observations are combined with numerical modeling to understand the physical processes and to show that asperities can remain strong, allowing frictional heating even after the onset of melting. 

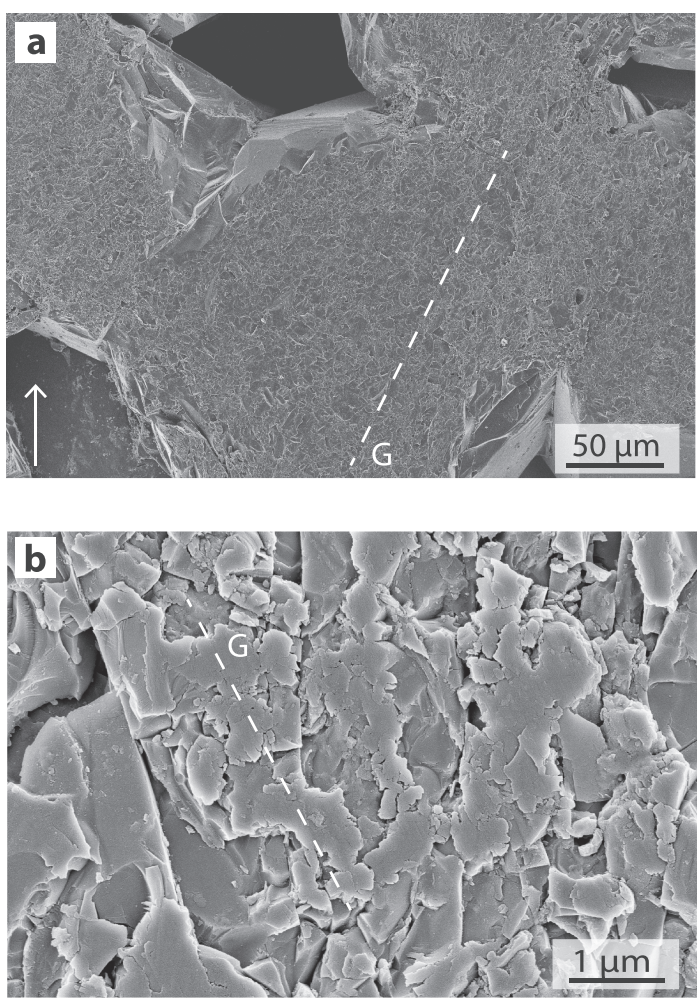

Figure 1. SE-SEM images of microstructures on an unslipped ground surface. (a) Low magnification view of the surface of a number of grains that have been ground wet with a fine diamond lap wheel. The ground surface is identifiable by the small-scale variations in contrast resulting from the locally uneven surface. The texture produced by grinding is, at this scale, consistent across the grain surfaces and is produced by fracturing and spalling during grinding. The direction of striations left by grinding is indicated by the dashed line " $G$ " and the orientation of slip if the sample were deformed is indicated by the arrow. No glassy, debris free patches are visible. (b) At high magnification small, we find locally striated zones of finegrained material (clast diameters $\ll 1 \mu \mathrm{m}$ ). These regions range in diameter from $<1$ up to $10 \mu \mathrm{m}$ and cover $5-10 \%$ of the fault surface.

\section{Methods and Analysis}

\subsection{Starting Materials and Sample Preparation}

Cores of Fontainebleau Sandstone $(\phi=9.98 \mathrm{~mm}$ ) ground oblique to the axial loading direction were used to simulate fault interfaces (Figure 2). Fontainebleau Sandstone is an approximately equigranular, almost pure quartz sandstone with grain size between $\sim 180$ and $250 \mu \mathrm{m}$ and porosity between $6 \%$ and $7 \%$. The pore structure has characteristic angular nodal pores (diameters up to $100 \mu \mathrm{m}$ ) connected by narrow grain-interface microcracks. Undulose extinction and subgrains are relatively common, although the random orientations of extinction indicate deformation occurred prior to erosion and sedimentary deposition. Preexisting open intragranular microcracks are rare, although healed microcracks are common. Fluid inclusions containing multiple phases (mainly $\mathrm{H}_{2} \mathrm{O}$ and $\mathrm{CO}_{2}$ ) are numerous but heterogeneously distributed, occurring both within the detrital grains, where they decorate healed microfractures and along overgrowth boundaries between detrital grains and intergranular quartz cement. The total volume of fluid inclusions is between $0.01-0.1 \mathrm{vol}$. \% of the crystalline material, with an average inclusion size of $\sim 1.1 \mu \mathrm{m}^{3}$.

Impurities were measured using an EOL JXA-8530F Plus field-emission electron microprobe. Average composition is $99.84 \mathrm{wt} \% \mathrm{SiO}_{2}$. Upper limits for impurities are: aluminum $982 \mathrm{ppm}$, titanium $171 \mathrm{ppm}$, iron 125 ppm, potassium $66 \mathrm{ppm}$, and sodium $44 \mathrm{ppm}$ based on a 95\% confidence interval.

The fault surfaces were prepared using a fine lapping wheel, very low normal stresses $(<0.01 \mathrm{MPa})$ and a holder that allows surfaces to be accurately ground to different angles $\left(\theta_{r}\right)$ relative to the cylinder axis. Room temperature experiments were ground at $\theta_{r}=45-50^{\circ}$, allowing access to high normal stresses and stick-slip behavior at room temperature (Hayward \& Cox, 2017). Elevated temperature experiments were ground so $\theta_{r}=30^{\circ}$ (Hayward et al., 2016). For both types of experiment the two fault blocks were ground to an overall length of $21 \mathrm{~mm}$ and oven dried at $70{ }^{\circ} \mathrm{C}$ for at least $48 \mathrm{hr}$ prior to use. Specimens were loaded into a $0.25 \mathrm{~mm}$ thick annealed copper sleeve and then into either a thin-walled $(\sim 0.4 \mathrm{~mm})$ copper jacket for room temperature experiments, or a low-carbon mild steel jacket for the high-temperature experiments. For all data presented in this paper we have applied a correction to remove the strength contribution of the metal jacket assembly (Hayward \& Cox, 2017).

We characterized surface roughness of the preground surfaces using a Leica DCM8 optical surface measurement system. On the larger scale, surface topography is controlled by the intersection of the surface with the angular pore structure described above, resulting in voids up to $100 \mu \mathrm{m}$ deep. At the grain scale, asperity roughness is produced by the grinding process and has a depth of $<10 \mu \mathrm{m}$. However, surface topography estimates do not consider longer wavelength variations in height, interaction with the opposite surface, nor stress concentrations that are potentially imposed as a result of sample geometry and loading.

Scanning electron microscopy (SEM) imaging of a prepared but undeformed surface reveals extensive surface fracturing and spalling (Figure 1a). Wear tracks from the grinding process are faintly visible forming striations oblique to the slip direction (Line "G", Figure 1a). Minimal loose debris remains on the surface, although there are localized deposits or films of nanoparticles (Figure 1b). These deposits are generally submicron to $\sim 10 \mu \mathrm{m}$ in length and have serrated to lobate edges formed by fracturing and shearing of the nanomaterial under saturated conditions. Individual larger particles (diameters $<200 \mathrm{~nm}$ ) can be seen within the fine-grained matrix. Surfaces of the nanoparticle deposits are striated in the direction of grinding, with the occasional chatter marks resulting from the interaction between asperities and loose particles. Using FIBSEM we milled a cross section through a striated region, revealing that the fine-grained layer forms a film 10-200 $\mathrm{nm}$ thick. The fracture damage zone from grinding is up to $400 \mathrm{~nm}$ wide. 
Table 1

Room Temperature Experiments

\begin{tabular}{|c|c|c|c|c|c|c|}
\hline $\begin{array}{l}\text { Experiment } \\
\text { number }\end{array}$ & $\begin{array}{c}\text { No. of } \\
\text { slip event }\end{array}$ & $\begin{array}{l}\text { Reactivation } \\
\text { angle }\left(\theta_{\boldsymbol{r}}\right)\end{array}$ & $\begin{array}{c}\text { Stress } \\
\text { drop (MPa) }\end{array}$ & $\begin{array}{l}\text { Peak shear } \\
\text { stress (MPa) }\end{array}$ & $\begin{array}{l}\text { Shear displacement } \\
\text { during slip }(\mu \mathrm{m})\end{array}$ & $\begin{array}{l}\text { Maximum slip } \\
\text { velocity }(\mathrm{m} / \mathrm{s})\end{array}$ \\
\hline MIS047 & 1 & 45 & 18 & 201 & 27 & 0.04 \\
\hline MIS047 & 2 & 45 & 91 & 246 & 172 & 0.32 \\
\hline MIS047 & 3 & 45 & 152 & 325 & 311 & 0.54 \\
\hline MIS047 & 4 & 45 & 145 & 315 & 286 & 0.54 \\
\hline MIS047 & 5 & 45 & 132 & 300 & 253 & 0.47 \\
\hline MIS048 & 1 & 45 & 48 & 210 & 65 & 0.11 \\
\hline MIS048 & 2 & 45 & 77 & 241 & 150 & 0.26 \\
\hline MIS048 & 3 & 45 & 113 & 280 & 220 & 0.38 \\
\hline MIS048 & 4 & 45 & 143 & 309 & 279 & 0.45 \\
\hline MIS048 & 5 & 45 & 123 & 287 & 238 & 0.39 \\
\hline MIS049 & 1 & 50 & 89 & 255 & 201 & 0.40 \\
\hline MIS049 & 2 & 50 & 187 & 401 & 479 & 0.90 \\
\hline MIS049 & 3 & 50 & 180 & 415 & 412 & 0.72 \\
\hline MIS055 & 1 & 45 & 12 & 226 & 3 & 0.08 \\
\hline MIS055 & 2 & 45 & 90 & 256 & 158 & 0.26 \\
\hline MIS055 & 3 & 45 & 159 & 315 & 298 & 0.45 \\
\hline MIS055 & 4 & 45 & 138 & 307 & 260 & 0.45 \\
\hline MIS055 & 5 & 45 & 107 & 273 & 185 & 0.20 \\
\hline MIS055 & 6 & 45 & 79 & 254 & 132 & 0.06 \\
\hline MIS055 & 7 & 45 & 20 & 254 & 23 & 0.07 \\
\hline MIS056 & 2 & 50 & 65 & 211 & 128 & 0.27 \\
\hline MIS056 & 3 & 50 & 147 & 279 & 334 & 0.90 \\
\hline MIS056 & 4 & 50 & 156 & 310 & 340 & 0.72 \\
\hline
\end{tabular}

Note. $P_{c}=100 \mathrm{MPa}, \theta_{r}=45-50^{\circ}$.

\subsection{Experimental Apparatus and Procedure}

Two suites of experiments were undertaken using a Paterson internally heated, gas medium, rock deformation apparatus (Paterson, 1970). The first set of experiments were undertaken at room temperature (Table 1) and the second suite explored a temperature range from $T=500-927{ }^{\circ} \mathrm{C}$ (Table 2). A confining pressure $\left(P_{\mathrm{c}}\right)$ of $100 \mathrm{MPa}$ was applied during room temperature experiments. For the hightemperature experiments, varying $P_{\mathrm{c}}$ between 50 and $200 \mathrm{MPa}$ extended the range of normal stresses that could be achieved on the fault surfaces. Axial load was applied to the specimen by shortening the assembly at a constant rate between 0.36 and $3.63 \mu \mathrm{m} / \mathrm{s}$. Data were recorded using a digital data acquisition system (National Instruments LabView 11.0) with a sampling frequency of $100 \mathrm{~Hz}$ and recording frequency of $1 \mathrm{~Hz}$.

For a number of experiments, we estimate the velocity during rapid slip events using data obtained from a 1,550 nm fiber-based modified Mach-Zehnder interferometer (Hayward et al., 2016). This system uses a custom-built, noncontinuous, triggered system that records $2 \mathrm{~s}$ of data at a rate of $1 \mathrm{MHz}$ centered on the slip event. The displacement measured by the interferometric sensor is calibrated against the displacement transducer (LVDT) over an equivalent $2 \mathrm{~s}$ window. We use multiple beam paths to gain a greater understanding of the sample and machine response. Two beam paths are located on the exterior of the apparatus with optical collimators mounted at the top and bottom of the pressure vessel (Figure 2). The laser beam is reflected off the mirrors attached to the apparatus yoke providing a path that varies during deformation.

On a small number of room temperature experiments an additional beam path was used to understand the attenuation and potential damping of the displacement signal between the source and the exterior of the apparatus, where the majority of measurements are taken. For these experiments a third measurement path is located internally within the piston assembly above the sample (Figure 2b). A $1.9 \mathrm{~mm}$ diameter microcollimator is located within a $5 \mathrm{~mm}$ diameter conduit in the top ram and reflects the beam off an optically flat, highly polished tungsten carbide disk located at top of the partially stabilized zirconia piston in the sample assembly. 
Table 2

Experiments at Elevated Ambient Temperatures

\begin{tabular}{|c|c|c|c|c|c|c|c|}
\hline $\begin{array}{l}\text { Experiment } \\
\text { number }\end{array}$ & $\begin{array}{c}\text { No. of slip } \\
\text { event }\end{array}$ & $\begin{array}{c}\text { Confining } \\
\text { pressure }(\mathrm{MPa})\end{array}$ & $\begin{array}{c}\text { Ambient } \\
\text { temperature (K) }\end{array}$ & $\begin{array}{c}\text { Stress } \\
\text { drop (MPa) }\end{array}$ & $\begin{array}{l}\text { Peak shear } \\
\text { stress (MPa) }\end{array}$ & $\begin{array}{c}\text { Shear displacement } \\
\text { during slip }(\mu \mathrm{m})\end{array}$ & $\begin{array}{l}\text { Maximum slip } \\
\text { velocity }\left(\mathrm{m} \mathrm{s}^{-1}\right)\end{array}$ \\
\hline BIS010 & 1 & 100 & 1173 & 82 & 170 & 142 & 0.23 \\
\hline BIS011 & 1 & 100 & 923 & 49 & 151 & 83 & 0.08 \\
\hline BIS020 & 1 & 100 & 923 & 37 & 141 & 65 & 0.05 \\
\hline BIS029 & 1 & 100 & 1073 & 111 & 165 & 196 & 0.44 \\
\hline BIS030 & 1 & 100 & 973 & 33 & 137 & 54 & 0.03 \\
\hline BIS032 & 1 & 100 & 1123 & 73 & 159 & 126 & 0.18 \\
\hline BIS035 & 1 & 100 & 1173 & 90 & 168 & 158 & 0.28 \\
\hline BIS041 & 1 & 50 & 1173 & 53 & 93 & 106 & 0.12 \\
\hline BIS043 & 1 & 150 & 923 & 127 & 190 & 218 & 0.55 \\
\hline BIS048 & 1 & 50 & 973 & 19 & 71 & 35 & 0.01 \\
\hline BIS056 & 1 & 100 & 1173 & 54 & 146 & 96 & 0.10 \\
\hline BIS056 & 2 & 100 & 1173 & 74 & 157 & 130 & 0.19 \\
\hline BIS056 & 3 & 100 & 1173 & 72 & 151 & 128 & 0.18 \\
\hline BIS056 & 4 & 100 & 1173 & 68 & 148 & 123 & 0.16 \\
\hline BIS056 & 5 & 100 & 1173 & 68 & 147 & 119 & 0.20 \\
\hline BIS056 & 6 & 100 & 1173 & 75 & 151 & 132 & 0.04 \\
\hline BIS058 & 1 & 100 & 923 & 33 & 138 & 57 & 0.04 \\
\hline BIS058 & 3 & 100 & 923 & 35 & 132 & 63 & 0.04 \\
\hline BIS058 & 4 & 100 & 923 & 26 & 127 & 48 & 0.03 \\
\hline BIS059 & 2 & 100 & 1173 & 78 & 159 & 139 & 0.22 \\
\hline BIS059 & 3 & 100 & 1173 & 74 & 154 & 131 & 0.19 \\
\hline BIS059 & 4 & 100 & 1173 & 69 & 151 & 123 & 0.17 \\
\hline BIS059 & 5 & 100 & 1173 & 66 & 149 & 118 & 0.16 \\
\hline BIS059 & 6 & 100 & 1173 & 65 & 150 & 114 & 0.15 \\
\hline BIS060 & 1 & 100 & 1073 & 31 & 151 & 54 & 0.03 \\
\hline BIS060 & 2 & 100 & 1073 & 35 & 148 & 64 & 0.05 \\
\hline BIS060 & 3 & 100 & 1073 & 67 & 153 & 118 & 0.16 \\
\hline BIS060 & 4 & 100 & 1073 & 58 & 146 & 102 & 0.12 \\
\hline BIS060 & 6 & 100 & 1073 & 56 & 137 & 81 & 0.08 \\
\hline BIS060 & 7 & 100 & 1073 & 51 & 139 & 89 & 0.09 \\
\hline BIS060 & 8 & 100 & 1073 & 49 & 138 & 86 & 0.08 \\
\hline
\end{tabular}

Note. $\theta_{r}=30^{\circ}$.

\subsection{Data Processing}

Post-acquisition data processing was performed in MATLAB using custom scripts. Displacement data (LVDT and interferometer) were corrected for the elastic response of the apparatus to the applied load $\left(\sim 0.0149 \mathrm{~mm} / \mathrm{kN}\right.$; Hayward \& Cox, 2017). For experiments, where $\theta_{r}=45-50^{\circ}$ stress data have been corrected for the change in cross-sectional area of the slip interface during deformation. At the start of the experiment each slip surface is adjacent to and in alignment with the area of the opposing surface. However, with the onset of slip the fault surfaces move relative to each other and eventually their elliptical surface areas will no longer coincide. Any reduction in overlapping area increases stress on the remaining interface. No correction has been made for the $30^{\circ}$ experiments as there is essentially no change in the cross-sectional area during the $<1 \mathrm{~mm}$ of slip.

The interferometer measures displacement on the slip interface remotely; consequently, the signal is a summation of multiple components including the response to the slip event both from the sample and apparatus, as well as broad-spectrum ambient noise. Although slip velocity can be obtained by numerical differentiation of fault displacement, any velocities calculated from the raw signal amplify noise, significantly overestimating slip velocities on the fault surface. To reduce the impact of this noise, we have used a hard wavelet thresholding approach (Donoho et al., 1995) using biorthogonal wavelets (Cohen et al., 1992). A noise level threshold was estimated from the preslip quiescent period. This approach suppresses the noise while preserving the character of the displacement signal, most notably the temporal position of peaks and edges.

Once ambient noise has been removed a function is fitted to the signal to eliminate the effects of apparatus ringing on the estimated slip velocity. All fast slip events generate a machine response in the form of 
a

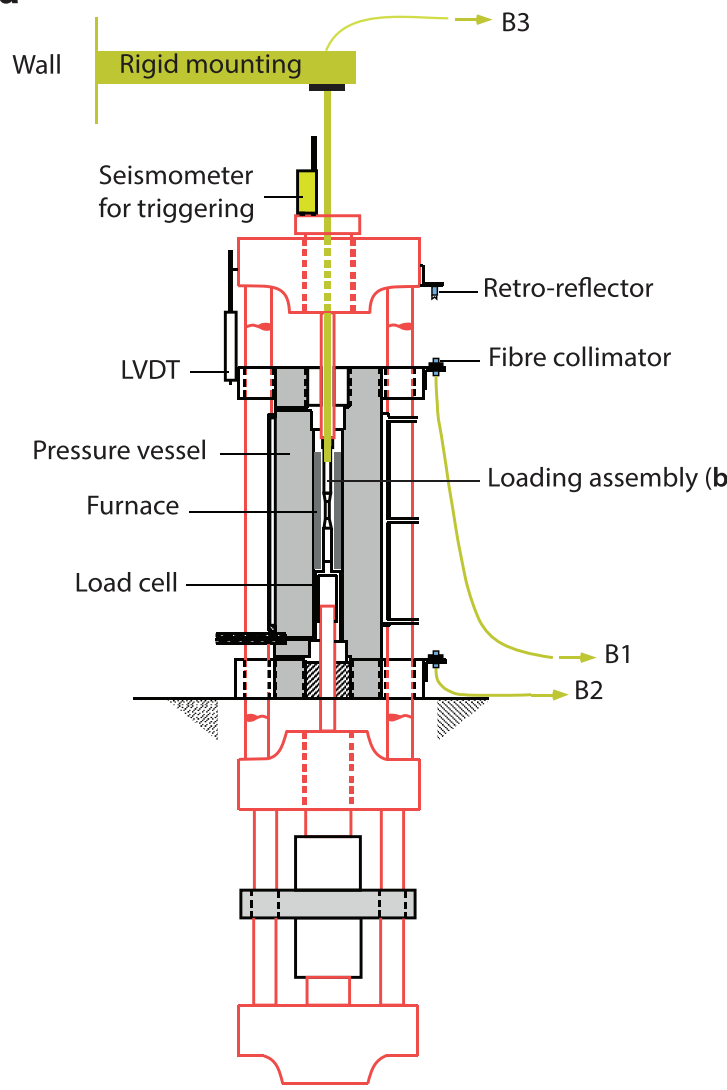

b

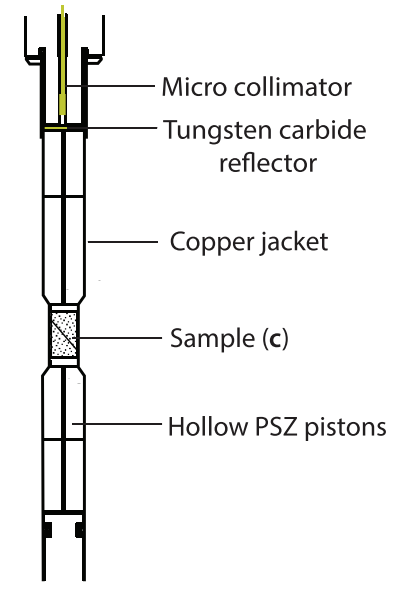

C

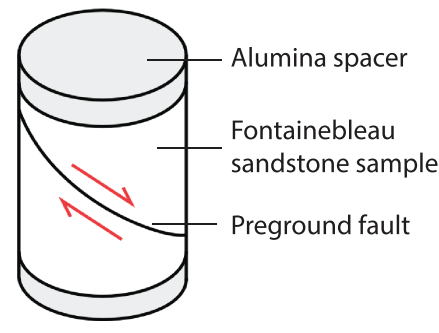

Figure 2. Schematic diagram showing apparatus, loading assembly, and sample. (a) Deformation apparatus showing main components. Loading frame is indicated in red. Interferometry system is shown in green. Points B1, B2, and B3 indicate the different fiber paths for the interferometry measurements. Two of the measurement points are located on the exterior of the apparatus with optical collimators mounted on the top and bottom of the pressure vessel. Reflectors are attached to the apparatus yoke and internally in the loading assembly. (b) Loading assembly showing location of the sample and third interferometry measurement point. (c) Sample configuration. The Fontainebleau sandstone sample has a preground fault oriented at either $30^{\circ}$ or $45-50^{\circ}$ to the sample shortening direction.

resonance at $\sim 1 \mathrm{kHz}$. Two different methods have been used to fit the data, with the approach being dependent on the size of the slip event. Large slip events, characterized by high velocities, large displacements, and large stress drops, are fitted with a sigmoid function (Figure 3a). Small, low-velocity slip events are fitted with a sigmoid with an exponential decay term representing the postseismic slip on the fault and possibly continued relaxation of the apparatus (Figure 3b). Processing the signal in this manner provides a conservative lower bound for sample slip velocity by minimizing higher-frequency changes in acceleration attributed to the response of the apparatus to the slip event.

For a small number of slip events, the magnitude of velocities estimated by our curve-fitting method have been compared to displacement data recorded internally within the sample assembly. Comparison of raw displacement data from the internal and external beam paths shows a phase shift between the two signals that is equivalent to the predicted time shift caused by elastic wave propagation between the fault surface and the sensor locations, assuming an average $P$ wave velocity equivalent to steel. High-frequency components of the signal are lost to apparatus attenuation. We find that the estimated slip durations for events recorded internally are shorter than those recorded on the outside of the apparatus and that the largest discrepancy occurs on small events, where external measurements tend to understate velocities. External measurement of small slip events also reveals that the step function associated with fast slip (modeled here as the sigmoid) can be overprinted by the onset of the machine resonance (a decaying sine wave), making the true size of the fast slip difficult to determine. Despite these technical limitations, especially with small events, 

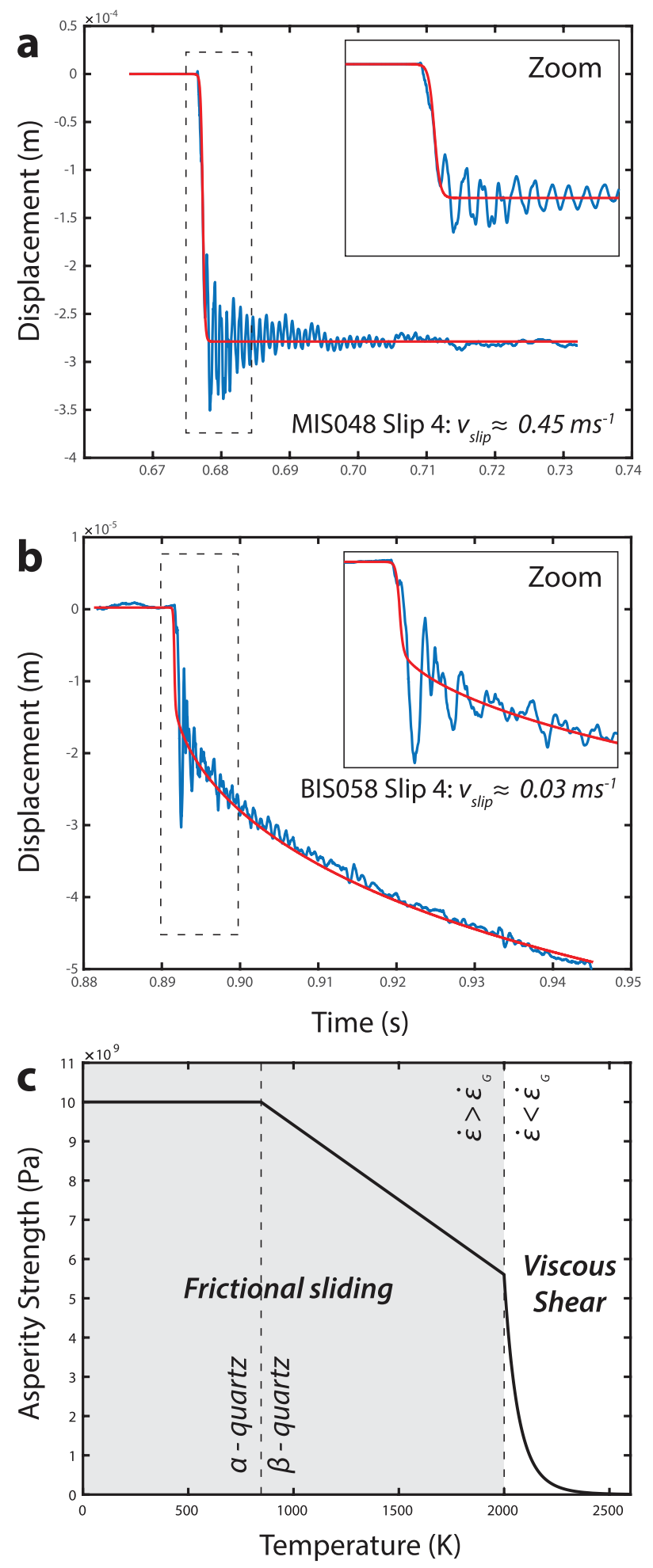

Figure 3. Model input parameters. (a, b) We show an example of the difference in slip behavior between a large and small slip event. The raw signal is shown in blue. To estimate maximum slip velocity, the large slip event is fitted with a sigmoid function and the small slip event is fitted with a sigmoid containing an exponential decay term. The fitted model is shown in red. (c) An example of the input model for asperity strength as a function of temperature. A constant strength is assumed up until the alpha-beta quartz transition. A linearly decaying strength is then applied until the temperature is reached where the strain rate is less than the critical strain rate (i.e., the molten asperity tip behaves as a liquid during shear). After this temperature, asperity strength is determined by the shear strength of the melt. 
observations support our assumption that the estimated velocities provide a conservative lower bound on the speed of slip.

\subsection{Microstructural Analysis}

Following the experiments, samples were retrieved from the pressure vessel and prepared for microstructural analysis by SEM. Two different techniques were used; the first involved exposing the slip surfaces by peeling away the jacket assembly and mounting the two sides of the fault so that the surface was flat and perpendicular to the electron beam. The second method involved stabilizing the fault and surrounding damage zone with a heat curing epoxy (Petropoxy). The sample was cut along the cylinder axis, perpendicular to the fault and parallel to the direction of slip, providing a cross-section view of the fault. Half of the sample was mounted in an epoxy block and polished using a progression of diamond pastes, 0.3-0.05 $\mu \mathrm{m} \mathrm{Al}_{2} \mathrm{O}_{3}$, and finishing with colloidal silica. Prior to imaging, fault surfaces were sputter coated with platinum, whereas polished blocks were coated with a thin layer of carbon to minimize charging effects.

Fault surface textures were analyzed using an immersion lens secondary electron (SE) detector of the highresolution Zeiss UltraPlus field emission SEM (FE-SEM) at the ANU Centre for Advanced Microscopy. Working conditions include $3.0-5.0 \mathrm{kV}$ accelerating voltage, $10 \mu \mathrm{m}$ objective aperture, and a working distance between 3 and $5 \mathrm{~mm}$.

Targeted areas of the fault surface were selected for additional examination using transmission electron microscopy (TEM). TEM sections 12-15 $\mu \mathrm{m}$ long, $5 \mu \mathrm{m}$ deep, and $<100 \mathrm{~nm}$ thick were milled using a Gaion beam in a Helios NanoLab 600 Dualbeam Focused Ion Beam SEM (FIB-SEM) at the ACT Node of the Australian National Fabrication Facility. FIB sections where protected from ion beam damage during milling by the deposition of a $1 \mu \mathrm{m}$ thick layer of platinum. Completed sections were manually removed from the sample using a glass filament mounted in a micromanipulator and placed on carbon film TEM grid. TEM analysis was undertaken using a Philips CM300 TEM operating at $300 \mathrm{kV}$ accelerating voltage. Our TEM foils are highly susceptible to electron beam damage, so the majority of TEM analysis was undertaken at low magnification (up to x15,000) using low-intensity illumination.

Polished blocks were analyzed using an Angle selective Backscattered electron (AsB) detector on a Zeiss UltraPlus FE-SEM. A working distance of $6.5 \mathrm{~mm}, 10.0 \mathrm{kV}$ accelerating voltage, and the use of a $60 \mu \mathrm{m}$ aperture allowed us to image the damage zones and fracture networks in high resolution. Analysis of the entire longitudinal section was achieved through automated stage control and image stitching.

\subsection{Estimating Asperity Temperature}

The major energy transfer during frictional slip is the conversion of kinetic energy into heat through frictional interaction of the surfaces. It is therefore surmised that any change in surface properties of a fault interface (which may potentially give rise to weakening mechanisms) will, to a large extent, be controlled by the heat input associated with frictional sliding and the ultimate asperity temperature. A benefit of having high temporal resolution measurements of displacement during slip is that it allows us to more accurately quantify heat production during stick-slip events produced using a triaxial apparatus. Unlike rotary shear apparatus, where a constant velocity may be achieved and maintained for distances of centimeters to hundreds of meters, triaxial stick-slip events may achieve velocities of $>1 \mathrm{~m} / \mathrm{s}$ over slip distances of tens to hundreds of microns. For small stick-slip events such as those presented here, an assumption of constant velocity would result in a substantial overestimation of heat production. In the following section we describe how maximum asperity temperature is estimated, allowing a comparison of the mechanical behavior with corresponding microstructural phenomena.

Each slip event recorded by the interferometer consists of three distinct phases: a loading phase where the rate of apparatus shortening is constant, resulting in the accumulation of stored elastic strain in the assembly and loading frame; a period of rapid displacement associated with fast slip on the fault; and finally, a period of postseismic relaxation which is also associated with a decaying vibration attributed to a slip induced resonance in the apparatus (Figures $3 \mathrm{a}$ and $3 \mathrm{~b}$ ). When calculating the maximum possible asperity temperature, we assume that the maximum time that asperities are in contact is equivalent to the duration of the rapid slip event (i.e., the second stage described above). 
Table 3

Model Parameters

\begin{tabular}{lll}
\hline Parameter & \multicolumn{1}{c}{ Value } & \multicolumn{1}{c}{ Source (where applicable) } \\
\hline $\begin{array}{l}\text { Density, } \beta \text {-Quartz } \\
\text { Thermal diffusivity, } \beta \text {-Quartz }\end{array}$ & $\begin{array}{l}2,530 \mathrm{~kg} / \mathrm{m}^{3} \\
1.4 \times 10^{-6} \mathrm{~m}^{2} / \mathrm{s}\end{array}$ & $\begin{array}{l}\text { Lakshtanov et al. (2006) } \\
\text { Branlund and Hofmeister (2007), } \\
\text { Gilbert and Mainprice (2009) } \\
\text { Richet et al. (1982) }\end{array}$ \\
$\begin{array}{l}\text { Specific heat capacity } \\
\text { Width of fault }\end{array}$ & $\begin{array}{l}1,165 \mathrm{~J} /(\mathrm{kg} \mathrm{K}) \\
\text { Estimated from microstructural observations. }\end{array}$ \\
$\begin{array}{l}1 \mu \mathrm{m} \text { Moding rate } \\
10^{6} \mathrm{samples} \mathrm{per} \mathrm{second}\end{array}$ & \\
Duration of time step & $5 \times 10^{-4} \mathrm{~m}$ & \\
Number of time steps & $1 \times 10^{-6} \mathrm{~s}$ & \\
Grid size & 100,000 & \\
Melting temperature of quartz & $1 \times 10^{-5} \mathrm{~m}$ & Bourova and Richet (1998) \\
Glass transition of fused quartz & $1673 \mathrm{~K}$ & Richet and Bottinga (1984) \\
\hline
\end{tabular}

For modeling asperity temperatures we make a number of assumptions. First, we assume that asperity contacts form a planar heat source (Jaeger, 1942) with heat input divided equally between the solid on either side of the interface. Second, we assume that, on the asperity and grain scale, the material within our samples is approximately homogeneous and that therefore a 1-D model gives a reasonable approximation of heat diffusion away from asperities using the general heat diffusion equation

$$
\rho C \frac{\mathrm{d} T(x, t)}{\mathrm{d} t}=\kappa \frac{\mathrm{d}^{2} T(x, t)}{\mathrm{d} x^{2}}+Q(x, t)
$$

where $\rho$ is the density, $C$ the specific heat, $T$ the temperature along the 1-D profile, $t$ is time, $\kappa$ the heat diffusivity, and $Q$ the heat flux. We define $x$ as the spatial coordinate with the origin, $x=0$, set to the location of the fault surface and positive $x$ pointing into the sample. We assume that heating is symmetric and hence only simulate one half of the sample. Model parameters and associated references are provided in Table 3.

The heat flux is only applied at $x=0$ and is determined by a frictional heating model

$$
Q(0, t)=\frac{1}{2} v(t) \tau(T)\left[H\left(t-t_{0}\right)-H\left(t-t_{1}\right)\right]
$$

where $v$ is the slip velocity estimated from laser interferometry, $\tau$, is the temperature-dependent asperity strength, and $H$ is the Heaviside function with $t_{0}$ and $t_{1}$ representing the start and end times of asperity contact, respectively. The leading one half is a result of our assumption of symmetry whereby the energy from frictional heating is partitioned equally to both sides of the fault.

Asperity strength, $\tau$, is determined using an approximation of asperity strength based on hardness-derived yield stresses (Figure 3c; see Evans, 1984; Goldsby \& Tullis, 2011). We estimate asperity strength based on the calculated temperature at each time step in the model. As slip rates in our experiments far exceed strain rates during the indentation hardness experiments used to estimate yield stresses, we estimate significantly larger asperity strengths at high temperatures. When model temperatures exceed the estimated melting temperature of $\beta$-quartz (1673 K, Bourova \& Richet, 1998) we use a conditional approach that considers the strain rate and relaxation time of the melt to determine asperity strength. This approach is discussed in detail in section 2.6.

The other boundary conditions used are

$$
\begin{gathered}
T(x, 0)=T_{\text {ambient }} \\
T\left(x_{\max }, t\right)=T_{\text {ambient }}
\end{gathered}
$$

that is, the model is started from ambient temperature and the nonslip end of the model is held constant at ambient temperature. We set the length of the system, $x_{\max }$, to $500 \mu \mathrm{m}$; this is of sufficient length that the boundary condition has no effect on the estimation of temperatures near the fault surface.

To compute the temporal evolution of the model, the coupled system of equations (1) and (2) are advanced in time using the implicit Crank-Nicolson scheme (Crank \& Nicolson, 1947) which approximates the temporal 
and spatial derivatives with central finite differences. For convenience, we use a time step matching the sampling rate of the interferometer $(1 \mathrm{MHz})$ which is within the Courant-Friedrichs-Lewy condition (Courant et al., 1967) for stability given the grid spacing used.

\subsection{Modeling the Strength and Behavior of Interfacial Melt}

When seismic slip occurs on our samples at high normal stresses, frictional interaction of the surfaces can result in extreme heating rates (in excess of $2 \times 10^{6} \mathrm{~K} / \mathrm{s}$ for durations potentially up to $1 \mathrm{~ms}$ ). Localized high temperatures on asperity contacts can melt the quartz surfaces, producing a silica melt (as will be shown in section 3.2) that rapidly quenches to glass as heat is lost through diffusion in the surrounding sandstone media. Given the high strain rates and short duration of slip events ( $\sim \mathrm{ms})$ in the present experiments, the rheology of the melt layer is very complex. Indeed, silica melt is a Newtonian fluid but, under the extreme conditions at asperity contacts, its apparent rheology will become non-Newtonian due to (i) the elastic response of the melt due to the sudden stress changes (e.g., Bottinga \& Richet, 1996) and (ii) viscous shear heating (e.g., Simmons et al., 1982) related to the very high shear rates at play. Unfortunately, knowledge of melt behavior under high pressures and strain rates, with the extreme heating and cooling rates of our experiments, largely does not exist. Therefore, in the context of this experimental study, we propose a first-order approach to the rheological behavior of the silica film formed on the fault plane during experiments.

First, the strain-rate-dependent melt viscosity, $\eta_{\text {srd }}$, at time $t$ with an associated temperature $T(t)$ from the model outlined in section 2.5 was calculated using the empirical model of Simmons et al. (1982). This model of $\eta_{\text {srd }}$ for silicate glasses was established from experimental observations of strain-rate-dependent viscosity where all effects (elastic response, shear heating, etc.) are at play:

$$
\eta_{\text {srd }}(T(t))=\eta(T(t))\left(1+\frac{\eta(T(t)) \dot{\varepsilon}(t)}{\sigma_{\infty}}\right)^{-1},
$$

with $\dot{\varepsilon}$ the strain rate at time $t, \eta(T(t))$ the Newtonian viscosity of silica at temperature $T(t)$, and $\sigma_{\infty}$ the maximum asymptotic shear strength of the melt, estimated to be $\sim 2 \mathrm{GPa}$. The value of $2 \mathrm{GPa}$ was chosen based on the fact that it provided plausible and consistent results across a range of experimental conditions. This value and its potential temperature dependence could be better constrained with experimental observations, however, no such data for silica presently exists in the literature. $\dot{\varepsilon}(t)$ is estimated as $v(t) / w_{\text {melt }}$, where the viscous shear with velocity $v$ is assumed to be accommodated uniformly across the width of melt layer $w_{\text {melt }} \cdot \eta(T(t))$ was calculated using the empirical Tammann-Vogel-Fulcher equation

$$
\log _{10} \eta(T(t))=-3.648+14,093.2 /(T(t)-546.2),
$$

determined by fitting the best viscosity data available for silica (see Doremus, 2002). Finally, the melt relaxation time, $\zeta$, can be approximated using the Maxwell relation $\zeta=\eta / G_{\infty}$ (Maxwell, 1867), with $G_{\infty}$, the elastic shear modulus at infinite frequency, estimated as $10^{10} \mathrm{~Pa}$ for silicate melts (Narayanaswamy, 1971; Rekhson et al., 1971). Using this first-order rheological model, asperity behavior was estimated using a conditional approach. For silicate melts, solid (glassy), and liquid behavior can be approximately separated given a critical strain rate $\dot{\varepsilon}_{g}(t) \sim 0.01 / \zeta(t)$ (Webb \& Dingwell, 1990). Consequently, we can assume that, if $\dot{\varepsilon}(t)>\dot{\varepsilon}_{g}(t)$, frictional sliding occurs at the asperity interface whereas if $\dot{\varepsilon}(t)<\dot{\varepsilon}_{g}(t)$, sliding is accommodated through viscous shear in the melt. In the latter case, the strength of the melt, $\tau_{\text {melt }}$ is estimated as $\tau_{\text {melt }}=\eta_{\text {srd }} \dot{\varepsilon}$. Although this last assumption is not strictly accurate for a non-Newtonian fluid, it provides a first-order approximation of potential asperity strength. The melt is assumed to transition back from viscous to frictional behavior when either of the following conditions are met:

$$
\begin{gathered}
\dot{\varepsilon}(t)>\dot{\varepsilon}_{g}(t), \text { or } \\
T(0, t)<T_{g} .
\end{gathered}
$$

$T_{g}$ in equation (8) is the glass transition temperature of the silica melt at the asperity surface. For our model we assume $T_{g}=1480 \mathrm{~K}$, the value measured by calorimetry at a constant cooling rate of $10 \mathrm{~K} / \mathrm{min}$ (Richet \& 

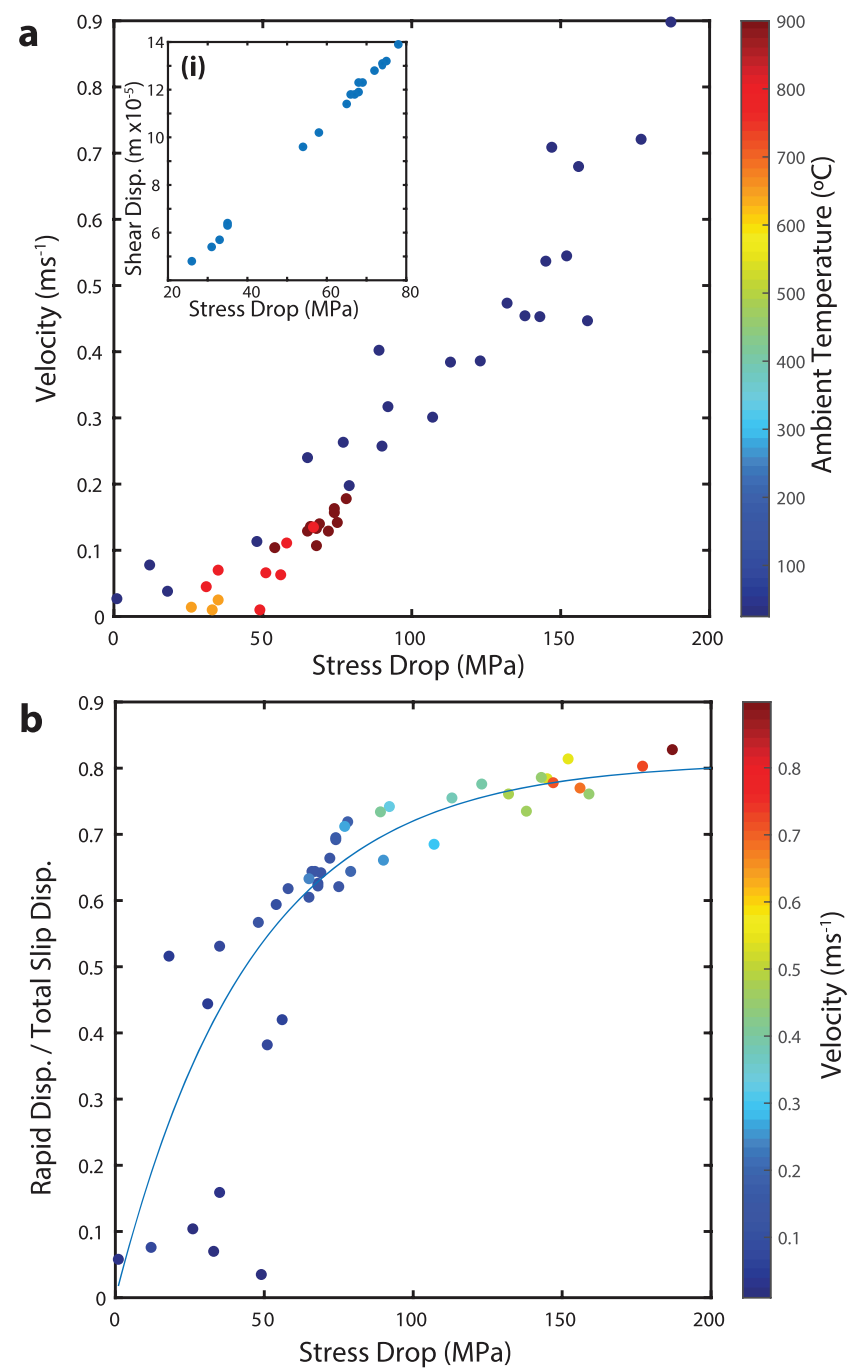

Figure 4. Mechanical results. (a) Approximately linear relationship $\left(\mathrm{r}^{2}=\right.$ 0.8 ) between the stress drop accompanying an episodic slip event and the maximum velocity recorded using the fitted signal from the interferometer. Data points are colored to indicate experimental ambient temperature. Inset (i) shows the linear relationship $\left(\mathrm{r}^{2}=0.97\right)$ between the total shear displacement recorded by the LVDT and the stress drop for each event. (b) With increasingly large events (high velocities, large stress drops, and displacements), a higher proportion of the total displacement recorded during the $2 \mathrm{~s}$ window centered on the slip event occurs as fast sliding. The fitted line indicates the ratio applied to displacement data to estimate maximum asperity contact distance for a given stress drop. Data points are colored to indicate the maximum slip velocity.
Bottinga, 1984). This is a simplification because the actual glass transition temperature depends on the cooling rate. However, as our model only considers the melting of asperities and not the reheating of previously melted areas this assumption has limited impact on model results. The main effect of neglecting variations of $T_{g}$ with cooling rate will be to potentially prolong the role of viscous behavior at the end of slip. The present model also assumes that the melt has a homogeneous pure silica composition and is free from clasts, bubbles, or chemical impurities.

\section{Results}

\subsection{Mechanical Results}

This study focuses on the results of 31 experiments where stick-slip behavior has been activated over a range of confining pressures and ambient temperatures (Tables 1 and 2). Behavioral transitions between stick-slip and stable sliding for Fontainebleau sandstone as a function of pressure and temperature are presented in Hayward et al. (2016). The behavior of faults investigated in this study is characterized by a period of essentially elastic loading followed by a poorly defined yield point and the onset of permanent deformation in the form of fracture development, asperity failure, and creep on the fault surface. After varying amounts of strain-hardening stable sliding the faults transition into a stick-slip regime. Stick-slip behavior is manifest by periods of elastic loading interspersed with large stress drops (between 6 and $127 \mathrm{MPa}$ or approximately 3-67\% of peak shear stress) and slip velocities of up to $0.9 \mathrm{~m} / \mathrm{s}$ over displacements between 3 and $479 \mu \mathrm{m}$.

The occurrence of stick-slip at temperatures above $600{ }^{\circ} \mathrm{C}$ is in contrast to many classic triaxial slip experiments on crustal rocks that show a transition from stick-slip to stable sliding with increasing temperature (Lockner $\&$ Byerlee, 1986; Stesky et al., 1974). This phenomenon is widely attributed to a transition from velocity-weakening to velocity-strengthening behavior at temperatures above $\sim 350{ }^{\circ} \mathrm{C}$. However, more recent studies (e.g., Hayward et al., 2016; Mitchell et al., 2016) have found the transition between stick-slip and stable sliding at elevated temperatures can be more complex. Variations in behavior between different experiments are resultant on numerous factors including apparatus stiffness, the potential onset (or suppression) of crystal plasticity and temperature-induced changes in the properties of minerals (e.g., anisotropic thermal expansion, softening of indentation hardness, and phase transitions). From the collected mechanical data, we find that there is an approximately linear relationship between estimated slip velocity and stress drop (Figure 4a, squared multiple correlation $\left(R^{2}\right)$ equal to 0.8$)$ and also between stress drop and total shear displacement recorded during the $2 \mathrm{~s}$ acquisition window (Figure $\left.4 \mathrm{a}(\mathrm{i}), R^{2}=0.97\right)$. These linear relationships allow an estimation of slip velocity for experiments where velocity measurements are not available. Multiple linear regression produces a $R^{2}$ equal to 0.87 and all variables are significant.

As rapid slip events increase in size and velocity, a greater proportion of recorded displacement occurs during the fast slip event rather than as postseismic creep or sample and/or apparatus relaxation (Figure 4b). The data have been fitted with a half sigmoid function, assuming that at zero stress drop there is no displacement. In experiments where interferometry data are not available, the ratio given by the fitted function is used in conjunction with the total displacement measured using the LVDT to provide an estimate of the amount of slip occurring during fast slip. 

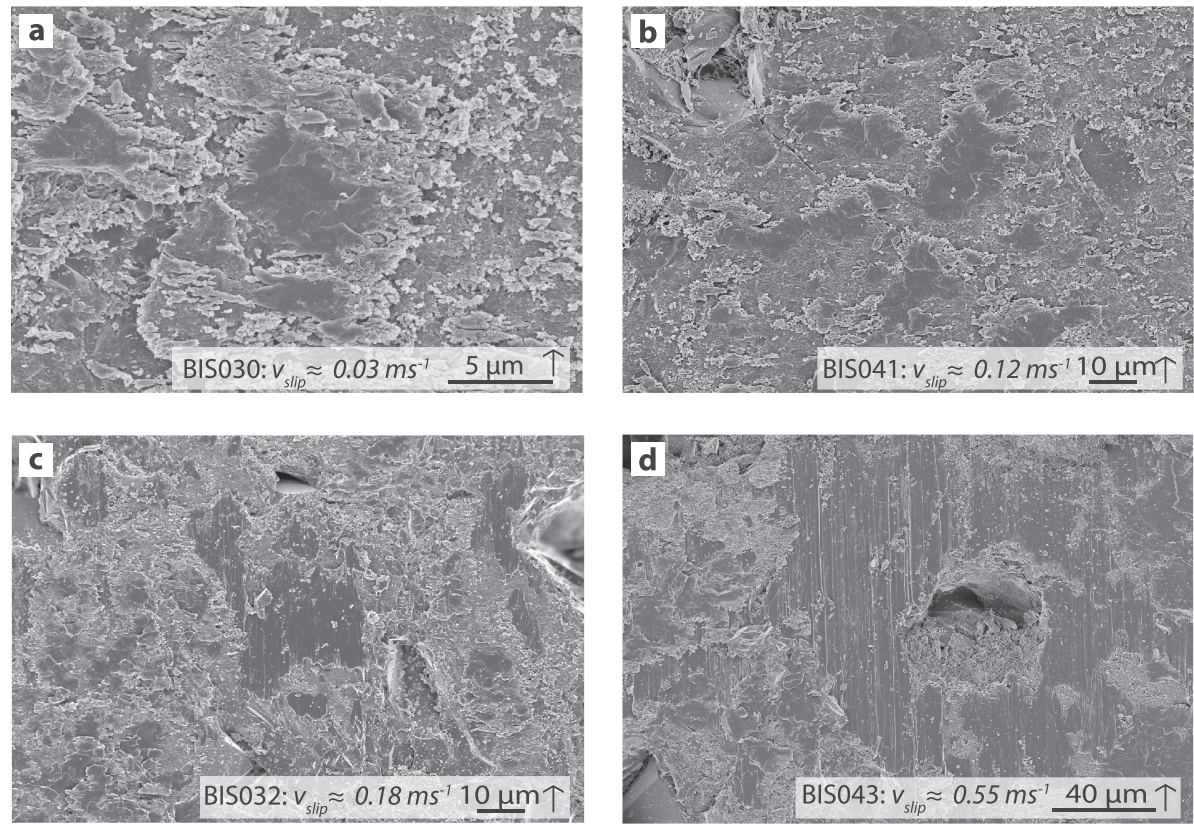

Figure 5. SE-SEM images of microstructures on the fault surfaces as a function of slip velocity. Experiment number and modeled maximum asperity temperature are indicated. Arrows show the direction of slip of the imaged surface. (a) Small (diameter $<10 \mu \mathrm{m}$ ), fractured, debris-free patches on the surface of a fault where slip velocitiy is $<0.1 \mathrm{~m} / \mathrm{s}$. Patches are gennerally rimmed by fractures and slivers of material that form perpendicular to the slip direction. (b-d) At increasing slip velocities, patches increase in size and density. This trend continues until at velocities $>0.1 \mathrm{~m} / \mathrm{s}$ sheared melt regions also develop on the fault surfaces. Sheared melt regions show continuous striations in the melt layer up to $178 \mu \mathrm{m}$ in length.

A number of the experiments were halted after a single slip event. This allowed us to microstructurally isolate surface expressions of flash heating associated with only one slip event. By limiting total slip, these experiments minimized the complication of overprinting structures and provided insights into fault behavior in the first tens to hundreds of microns of slip.

\subsection{Microstructural Analysis}

Microstructural analysis was undertaken on samples deformed until a single rapid slip event occurred. Two key microstructures are recognized: fractured glass "patches" and viscously sheared glass films. On all fault surfaces there are regions or patches that are conspicuous by the absence of wear debris. These regions have a fractured surface, that is approximately parallel to the fault interface and fringed by fractures forming slivers of material that are aligned perpendicular to the direction of slip (Figure 5). TEM analysis shows that these patches have a surface layer of partly to completely amorphous material, recognizable by a uniform intensity and the absence diffraction contrast (Figure 6). Selected area electron diffraction of the amorphous material shows a broad diffuse ring around the central transmitted beam, reflecting the lack of long-range crystalline order (Figure 6(iii)). Where crystalline clasts are present in the amorphous layer, they are conspicuous by having varying diffraction contrast and SAED shows diffraction spots within the diffuse amorphous halo (Figures 6(i) and 6(ii)). The abundance of clasts appears to be inversely proportional to the estimated slip velocities.

The viscously sheared glass films occur on fault surfaces where slip velocities have exceeded $10 \mathrm{~cm} / \mathrm{s}($ areas range in size from less than $1 \mu \mathrm{m}^{2}$ to in excess of $200 \mu \mathrm{m}^{2}$ ). These regions characteristically display striations, drawn-out, ribbon-like filaments, and textures that are consistent with the flow of a viscous melt (Figures 5c and $5 \mathrm{~d}$ ). Striations are oriented approximately parallel to the direction of slip. The amorphous structure of the film is confirmed using TEM (Figure 6c). In the following descriptions, we refer to areas with melt-flow textures as "melt" to highlight the fact that it has behaved as a liquid during the experiments, whereas we describe the amorphous material in the "patches" as being "glass." Compositional analysis (energy 

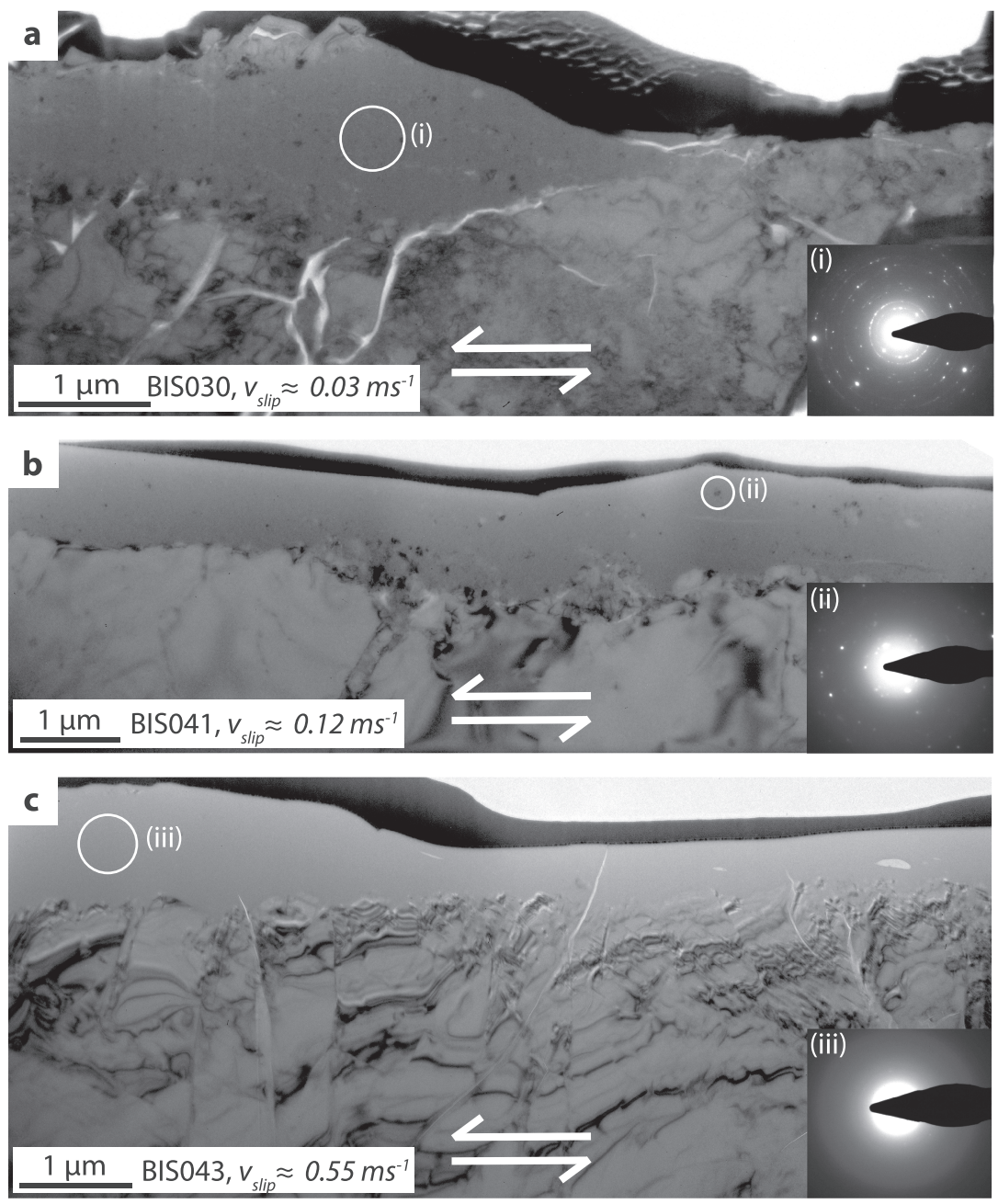

Figure 6. TEM images of FIB sections milled on samples with progressively higher slip velocities. Low magnification bright-field images of FIB sections. Arrows indicate the relative movement of the fault. The black layer is a coating of platinum deposited prior to milling the section to protect the sample from ion beam damage. The amorphous film is the 0.5-1.5 $\mu \mathrm{m}$ thick, largely homogeneous layer of uniform contrast between the platinum and the crystalline substrate. The quartz wall rock is recognizable by the variable diffraction contrast (Bragg contours). (a) Sample with the lowest slip velocity. Glass layer has the highest density of clasts, indicating lower temperatures and incomplete melting. Large clasts immediately below platinum layer at the top of the sample are likely wall-rock from other fault block. (b) Higher slip velocity than (a). Clasts are distributed throughout the glass, although their density is less than (a), indicating a higher maximum asperity temperature. (c) The amorphous layer has very few entrained crystalline clasts, with those present being located adjacent to the melt substrate boundary. A number of vesicles are present in the melt layer and have been elongated during slip, confirming that the melt has accommodated shear.

dispersive analysis of X-rays) of the amorphous layers by both SEM and TEM-EDS indicates that they are essentially pure silica with impurities being below limits of detection.

Cross sections of the slipped faults examined with BSE-SEM show the development of melt and glass within the fault core in highly stressed zones such as at asperity or grain-to-grain contacts (Figure 7). In BSE images at low magnification the amorphous silica appears brighter due to its nonporous structure compared with the surrounding gouge. However, at high magnification the silica has a lower back-scattered electron intensity than the adjacent crystalline quartz, corresponding to reduced electron scattering resulting from the loss of long-range order and up to $20 \%$ reduction in density. These observations are consistent with the variations in electron scattering intensity in frictional melt found in shocked quartz experiments (Kowitz et al., 2013). Melt and glass form layers $\sim 1-2 \mu \mathrm{m}$ thick. Microstructures within the melt layer readily correlate with textures observed using SE-SEM and TEM. These textures include the formation of drawn out filaments, 

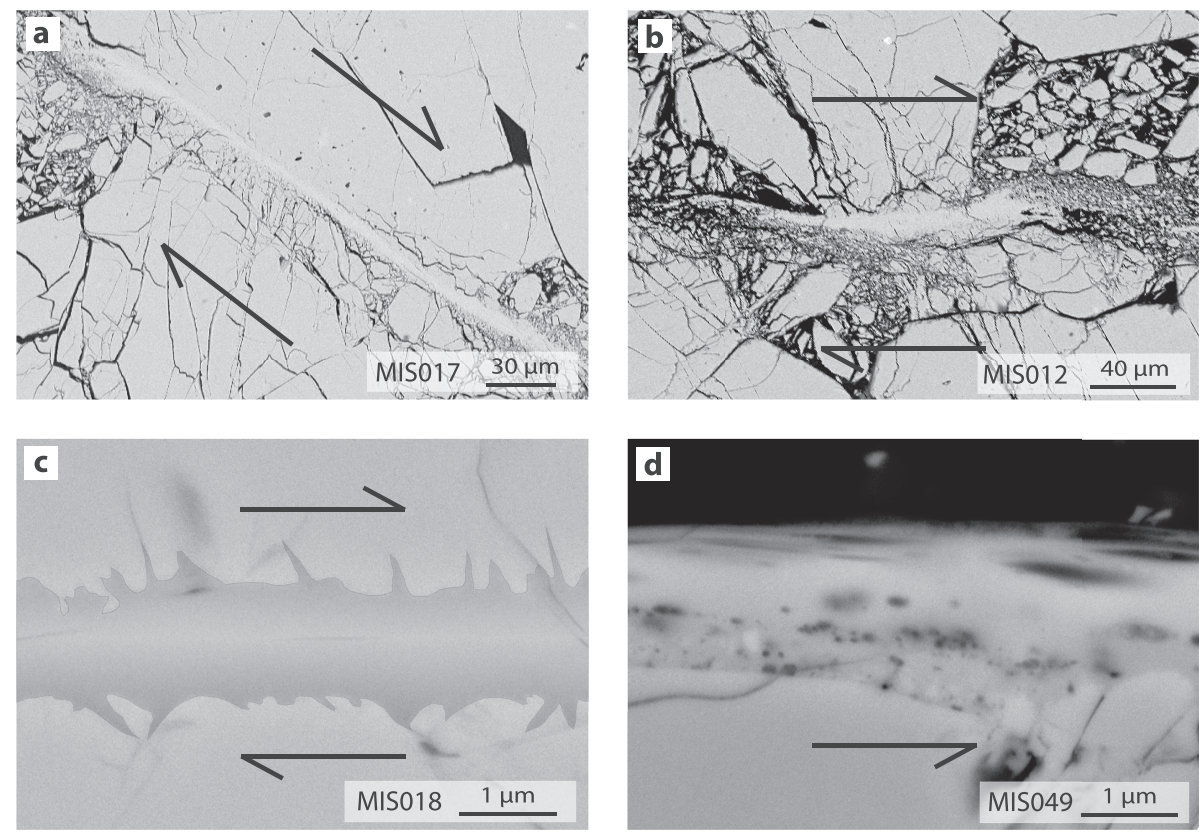

Figure 7. BSE-SEM images of cross sections of faults. Images show glass formation at asperity contacts over a range of magnifications. Arrows indicate the relative movement of the fault surfaces. (a, b) Evidence of frictional heating at asperity contact shown by a vein of glass in the center of the fault. Note that slip results in the destruction of the asperity with often intense fracturing, translation, and rotation of the wall rock into adjacent pores. (c) High magnification image of the glass vein at an asperity contact. Here the vein welds the two surfaces of the fault. A semitransparent overlay is used to enhance the contrast between the glass and quartz wall rock. Note the variation in topography along the melt wall-rock boundary. (d) Image showing sheared vesicles within the melted layer. Vesicles shown are increasingly elongated toward the center of the fault indicating a strain gradient within the melt layer.

strained vesicles, and the melt invasion of adjacent fractures forming an uneven boundary between the melt and the quartz substrate.

\subsubsection{Correlation Between Slip Velocity and Microstructure}

In experiments with the lowest estimated slip velocities (e.g., BIS030, $v_{\text {slip }} \sim 0.03 \mathrm{~m} / \mathrm{s}$ ), glass patches occur infrequently and have a diameter $<10 \mu \mathrm{m}$ (Figure 5a). TEM imaging shows that glass patches have a high clast density, with clasts distributed throughout the layer (Figure 6a). It is possible that the localized areas of the fault surface covered with a nanoparticle film formed during sample preparation may preferentially melt with the addition of heat during slip. The nanoparticles have a large surface area, enhancing melting rates and partial melting of larger clasts is consistent with the presence of crystalline clasts within glass layer. The thickness of the glass layer is significantly larger (3-5 times greater) than the thickness of the grinding related damage. There is no conclusive evidence of shearing within the glass (e.g., no elongate vesicles, melt flow textures). Cylindroidal structures occur locally on the surface of the glass patches. These roll-like textures are elongated perpendicular to the direction of slip and are interpreted to be a product of wear between abutting asperities (Figure 8a).

As slip velocities increase and the slip events become larger, glass patches increase in size and density. At an estimated slip velocity, $v_{\text {slip }} \sim 0.12 \mathrm{~m} /$ sthe average width of asperity contacts perpendicular to the slip direction is $10-20 \mu \mathrm{m}$, whereas lengths in the direction of slip can be up to $40 \mu \mathrm{m}$ (Figure $5 \mathrm{~b}$ ). TEM imaging of a FIB foil milled on a fractured patch shows that the glass layer contains numerous clasts (Figure 6b), but significantly less than those described above. The density of clasts is highest at the melt-wallrock boundary. Again, there is no microstructural evidence to indicate that shear is accommodated within the glass layer.

Above velocities of $0.15 \mathrm{~m} / \mathrm{s}$, fault surfaces have both fractured glass patches and zones of sheared melt (Figure $5 \mathrm{c}, v_{\text {slip }} \sim 0.18 \mathrm{~m} / \mathrm{s}$ ). Sheared melt patches range in width from 10-50 $\mu \mathrm{m}$ with continuous sheared textures over distances up to 40-50 $\mu \mathrm{m}$. Events with the highest velocity and largest displacement have melt films with continuous striations up to $\sim 180 \mu \mathrm{m}$ in length. Fractured patches still exist but are typically 

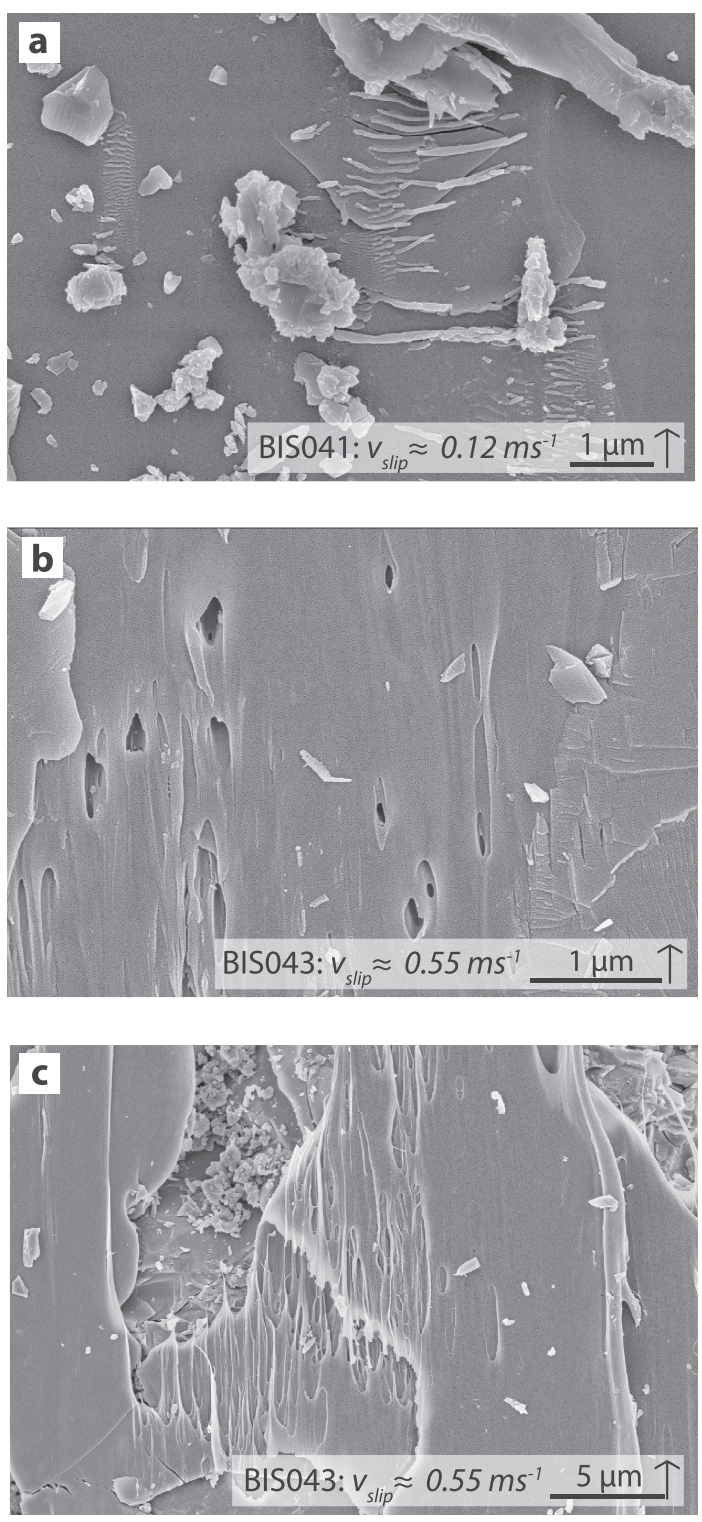

Figure 8. SE-SEM images of microstructures on fault interfaces that show evidence of shear at asperity contacts. Arrows in scale box indicate direction of slip of the imaged surface. (a) Cylindrical structures formed on fractured patches. These rolls likely formed as the result of abrasive wear of a softer material. Long axes of rolls again from perpendicular to the slip direction. (b) A fractured region with elongate vesicles. Vesicle elongation is evidence of shear within the melt layer. The amount of shear is not homogenous throughout the region and remnant shapes of fluid inclusions occurs on less sheared vesicles. (c) Sheared melt-forming ribbon-like glass filaments. Lobate edges suggest a degree of lateral spread. adjacent to or on top of the viscously sheared melt, suggesting weldedshearing zones that have fractured after slip. A FIB section milled across the boundary between a sheared melt zone and fractured patch reveals a continuous amorphous film when imaged in TEM (Figure 6c). The amorphous layer has a very low clast density except immediately adjacent to the melt-wallrock boundary. Clasts entrained in the melt layer are commonly rounded in shape, indicating incomplete melting.

There is limited evidence of lateral extrusion with melt patches forming lobate flow fronts and no evidence of flow into adjacent pores. Locally, the melt layer has the appearance of a holey film where sheared vesicles have intersected the surface of the glass layer. In cross section vesicles act as a strain marker. Different samples exhibit different amounts of heterogeneity in strain across the melt layer; strain heterogeneity varies with both maximum slip velocity and ambient temperature. In samples deformed at room temperature with slip velocities, $0.4 \mathrm{~m} / \mathrm{s}<v_{\text {slip }}<0.9$ $\mathrm{m} / \mathrm{s}$ elongation is greatest in vesicles occurring near the center of the sheared zone (e.g., Figure 7d), with undeformed, circular vesicles near the melt wall rock boundary. In other samples deformed at elevated ambient temperatures, elongate vesicles are present across the entire melt zone, pointing to a more homogeneous accommodation of strain in the melt film (Figure 6c).

\subsubsection{Melt Generation Surfaces}

Central to understanding the evolution of asperity behavior and the process of flash heating is knowing whether glass patches and sheared melt represent asperity contacts. We assume that asperities will be the frictional contacts between the two surfaces, concentrating macroscopic stress onto small, localized areas. Given that heat generation during slip is directly proportional to contact stress, it follows that areas in contact will be the first to melt. In this section we present microstructural evidence that the melting process occurred on grain-to-grain contacts and, therefore, that the fractured glass patches on the fault surface do represent asperity contacts. However, the sheared melt textures produced during experiments where $v_{\text {slip }}>0.15 \mathrm{~m} / \mathrm{smay}$ not always represent the site of heat generation as the melt layer has likely been translated by shearing to an adjacent site.

The first set of microstructural observations that suggest melting occurred at asperity contacts is the heterogeneous propagation of the melt front through the crystalline substrate. Consistent with previous studies (e.g., Ainslie et al., 1961; Dash, 2002; Mei \& Lu, 2007) the microstructures indicate that melting preferentially occurs along free grain surfaces, grain boundaries, and fractures. Propagation of melting along surfaces formed by slip-induced fracturing causes significant variations in microscale topography along the melt-crystal interface (height variations up to $\sim 1 \mu \mathrm{m}$, Figure 6). We show two examples in Figure 9 of the heterogeneous propagation of the melt front. First, there is formation of melt-filled microfractures in the quartz along the melt-substrate boundary (Figure 9a). We use dark-field TEM imaging to highlight the amorphous material by enhancing sensitivity to crystal orientation. Melt-filled microfractures are highlighted by their uniform, higher intensity relative to the quartz substrate. These glass-filled fractures are up to $\sim 850 \mathrm{~nm}$ in length, $\sim 10-20 \mathrm{~nm}$ wide and have a consistent orientation, dipping between $\sim 30^{\circ}$ and $80^{\circ}$ away from the direction motion of the imaged fault block. At the grain scale these fractures are often asymmetric, forming preferentially on one side of the fault. As such, it is likely that they form as the result of transient tensional stresses in the wall rock during the slip, rather than being extension fractures formed from melt overpressure (Di Toro \& Pennacchioni, 2005; Nielsen et al., 2010). In the second example we show 

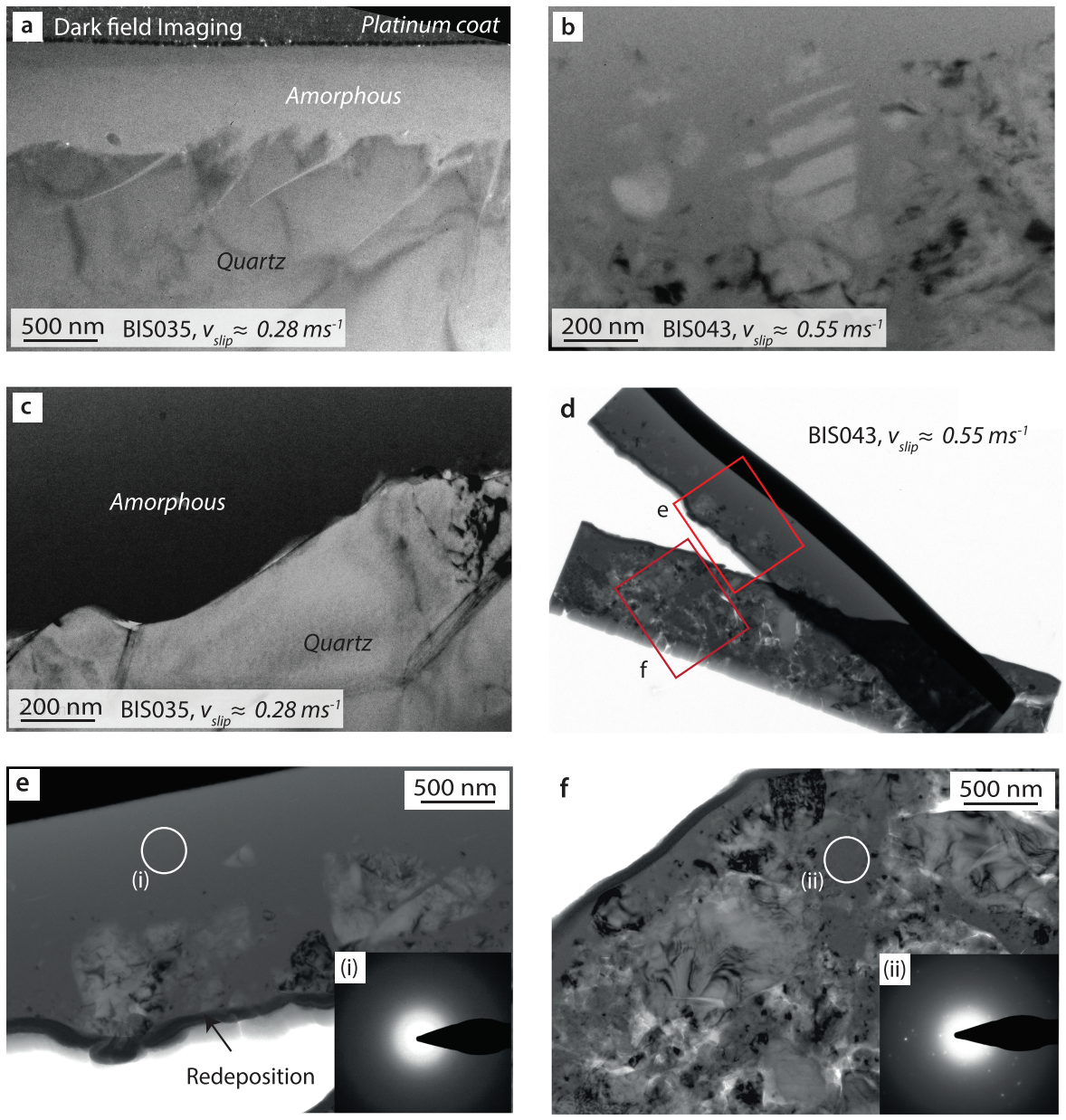

Figure 9. TEM images of melting process. (a) Dark-field image highlighting melt-filled fractures along the quartz-melt boundary. (b) Melting occurs preferentially along fractures and exposed surfaces. Note that the consistent orientation of grains suggests limited translation or rotation of the clasts (i.e., the clasts are not gouge but rather a highly fractured, in situ wall rock). (c) Sharp boundary between melt and the crystalline substrate (width of $<10 \mathrm{~nm}$ ). Here the sample has been tilted so that the crystalline material diffracts less strongly than the amorphous material making the intensity of the melt less than quartz substrate. (d) Low magnification image of TEM foil. The upper and lower portion of the foil separated during removal from the milling site due to a lack of cohesion between the melt layer and underlying substrate. The dark layer at the top of the section is the platinum coat deposited to protect the sample during milling, the $100 \mu \mathrm{m}$ thick dark layer at the boundary of the two segments (arrow in image e) results of redeposition of material during milling. Locations of images "e" and " $\mathrm{f}$ " are indicated in red. (e) Glass layer containing a number of comparative large $(<1 \mu \mathrm{m})$ clasts, some of which contain one or more melt-filled factures. (f) Substrate is composed of a porous agglomeration of randomly oriented particles (most likely accumulated gouge). The diffraction pattern collected at area (d) shows the presence of amorphous material within the substrate. Porous regions are indicated by areas of very high electron intensity (white regions).

a series of melt-filled fractures cutting through a crystalline clast that is surrounded by melt (Figure 9b). The different parts of the clast share a similar crystallographic orientation to both surrounding clasts and also the substrate, indicating that the clast likely has not been rotated from its original orientation. We suggest that both these examples show different stages of the in situ propagation of the melt front through a fractured substrate.

Another key question is whether the amorphous material forms through thermal melting or by another process such as through the accumulation of a high density of lattice defects. Although this is a difficult question to answer definitively, the following observations, in addition to the heterogeneous propagation of a melt front described above, support the notion of thermal melting. The width of the glass-quartz interface boundary is narrow, with many interfaces being less than $10 \mathrm{~nm}$ wide (e.g., Figure 8c). Sharp interface boundaries 
are consistent with observations on melt-crystal interfaces during thermal induced melting (Dell'Angelo \& Tullis, 1988). There is no evidence to indicate dislocation mobility during the experiments nor is there a high dislocation density in quartz immediately adjacent to a melt layer.

The difference between an asperity contact and a surface where the melt cover has been transposed from an adjacent contact is most easily seen in cross section (e.g., Figures 7a and 7b). In Figure 9d, we have milled a FIB section into a region where the melt film has sheared onto incohesive accumulation of wear debris adjacent to an asperity contact. While the melt layer still forms an amorphous film on the surface, the substrate consists of an agglomeration of irregularly oriented grains (diameter from $<100 \mathrm{~nm}$ to $1.5 \mu \mathrm{m}$ ) interspersed with melt and voids/pores. In a number of locations nanocrystalline particles (grain diameter $<100 \mathrm{~nm}$ ) are located within an amorphous matrix. Porosity is variable within the substrate, with higher porosity regions being located either adjacent to clasts or away from the glass-substrate boundary.

\subsection{Modeling Asperity Temperature and Rheology}

We use a 1-D finite difference heat diffusion model to estimate asperity temperature during slip for experiments undertaken at elevated ambient temperatures (for results, see Table 4). The differentiation of the fitted sigmoid function is used as the sliding velocity input (i.e., the velocity is a Gaussian function with respect to time, Figure 10a). Heat flux per unit area is estimated by the combined velocity model and temperaturedependent asperity strength (Figure 3c). A diffusion term allows for the dissipation of heat into the surrounding rock. An example of the temperature profile over time at the fault interface is shown in Figure 10b.

During slip on faults with high maximum slip velocities $\left(v_{\text {slip }}>0.15 \mathrm{~m} / \mathrm{s}\right)$, slip transitions from being accommodated by frictional sliding to viscously shearing within the melt layer. Initially the transition was modeled as a hard threshold based on the material properties of either quartz or silica glass, respectively. The hard threshold resulted in rapid cycling between heating and cooling as the model transitioned between heatproducing frictional sliding and the temperature sensitive viscous shear. In turn the rapid temperature changes produced oscillations in asperity strength (Figure 10c). However, the reality of this transition is almost certainly more complicated, likely with a gradual transition in the mode of strain accommodation at asperity tips resulting from heterogeneous contact stresses and contact times. To model this complexity in a simplifying way, we introduced a linear transition which allows viscous strain to be gradually accommodated from $85 \%$ of the relaxation time, resulting in a smooth strength profile (Figure 10c).

The transition from frictional sliding to viscous shear results in an increase in the rate of asperity weakening. The rapid decrease in strength also reduces heating efficiency. Experiments with low maximum slip velocities $\left(v_{\text {slip }}<0.15 \mathrm{~m} / \mathrm{s}\right)$ do not transition from frictional sliding to viscous shear during slip as sliding rates, although low, are too high to allow the highly viscous asperity contacts to cross the glass transition. Upon the cessation of slip strain rates tend to zero. If asperities have melted, the end of slip is accompanied by significant weakening with individual asperity strength approaching zero (the large dip in Figure 10c, see also Table 4). This postslip weakening occurs as the strain rate falls below the critical strain rate, allowing the asperity contact to behave as a viscous fluid. Strength is regained rapidly when the asperity temperature decreases below that of the glass transition. How this postslip weakening is influenced by a cooling-ratedependent glass transition temperature is to be the subject of future work.

When the modeled maximum asperity temperatures are plotted as a function of the displacement during rapid slip there are two regimes (Figure 10d). First, for low slip velocities $\left(v_{\text {slip }}<0.15 \mathrm{~m} / \mathrm{s}\right.$ ) there is an approximate linear increase in temperature with increasing slip displacement. As slip velocities increase, $v_{\text {slip }}>0.15$ $\mathrm{m} / \mathrm{s}$, the gradient between asperity temperature and slip displacement decreases, reflecting the transition toward viscous behavior. The intersection of the asymptotes of the two curves coincides with the onset of microstructurally observed sheared melt and curbing of the efficiency of heat generation at the asperity contacts. Small increases in temperature result in large increases in velocity and displacement, supporting the idea of weakening at the asperity tips following the transition to viscous shear.

In Figure 10e, we compare viscosity and relaxation time to the experimental data and microstructural observations. We find that experiments reach maximum temperatures between 1215 and $2494 \mathrm{~K}$. Temperature at the onset of viscous shear (weakening point) is approximately $2371 \mathrm{~K} \pm 60 \mathrm{~K}$. The wide temperature range reflects the sensitivity of the brittle viscous transition to the instantaneous slip velocity. Weakening distances, 
Table 4

Results of Thermal and Rheological Modeling

\begin{tabular}{|c|c|c|c|c|c|c|c|c|c|c|}
\hline $\begin{array}{l}\text { Exp. } \\
\text { No. }\end{array}$ & $\begin{array}{c}\text { No. of } \\
\text { slip event }\end{array}$ & $\begin{array}{c}\text { Max. } \\
v_{\text {slip }}(\mathrm{m} / \mathrm{s})\end{array}$ & $\begin{array}{l}\text { Weak. } \\
\text { Temp.. }{ }^{\text {a }}(\mathrm{K})\end{array}$ & $\begin{array}{l}\text { Max. } \\
\text { temp. (K) }\end{array}$ & $\begin{array}{c}\text { Weak. } \\
\text { Dist. }{ }^{\mathrm{a}}(\mu \mathrm{m})\end{array}$ & $\begin{array}{c}\text { Modeled slip } \\
\text { accommodated by } \\
\text { viscous shear }(\mu \mathrm{m})\end{array}$ & $\begin{array}{l}\text { Evidence of } \\
\text { cont. viscous } \\
\text { shear }(\mu \mathrm{m})\end{array}$ & $\begin{array}{l}\text { Avg. Asp. } \\
\text { Temp a at } \\
\text { weak. (K) }\end{array}$ & $\begin{array}{l}\text { Max. Avg. } \\
\text { Asp. } \\
\text { Temp (K) }\end{array}$ & Notes \\
\hline BIS010 & 1 & 0.23 & 2366 & 2383 & 43 & 99 & 95 & 2353 & 2356 & \\
\hline BIS011 & 1 & 0.08 & & 1819 & & & & & 1811 & \\
\hline BIS020 & 1 & 0.05 & & 1564 & & & & & 1561 & \\
\hline BIS029 & 1 & 0.44 & 2411 & 2465 & 39 & 157 & No images & 2397 & 2422 & \\
\hline BIS030 & 1 & 0.03 & & 1448 & & & & & 1447 & \\
\hline BIS032 & 1 & 0.18 & 2343 & 2347 & 50 & 76 & 76 & 2317 & 2320 & \\
\hline BIS035 & 1 & 0.28 & 2378 & 2411 & 40 & 118 & 118 & 2365 & 2376 & \\
\hline BIS041 & 1 & 0.12 & & 2222 & & & & & 2199 & $\begin{array}{l}\text { Weakening after } \\
\text { slip }\end{array}$ \\
\hline BIS043 & 1 & 0.55 & 2431 & 2494 & 41 & 177 & 178 & 2419 & 2433 & \\
\hline BIS048 & 1 & 0.01 & & 1215 & & & & & 1215 & \\
\hline BIS056 & 1 & 0.10 & & 2130 & & & & & 2117 & $\begin{array}{l}\text { Weakening after } \\
\text { slip }\end{array}$ \\
\hline BIS056 & 2 & 0.19 & 2349 & 2357 & 46 & 84 & $\begin{array}{c}\text { Multiple slip } \\
\text { events }\end{array}$ & 2328 & 2332 & \\
\hline BIS056 & 3 & 0.18 & 2346 & 2352 & 47 & 81 & $\begin{array}{l}\text { Multiple slip } \\
\text { events }\end{array}$ & 2335 & 2335 & \\
\hline BIS056 & 4 & 0.16 & 2336 & 2339 & 49 & 74 & $\begin{array}{c}\text { Multiple slip } \\
\text { events }\end{array}$ & 2315 & 2318 & \\
\hline BIS056 & 5 & 0.20 & 2329 & 2331 & 51 & 68 & & 2293 & 2301 & \\
\hline BIS056 & 6 & 0.04 & 2352 & 2362 & 46 & 86 & $\begin{array}{c}\text { Multiple slip } \\
\text { events }\end{array}$ & 2333 & 2339 & \\
\hline BIS058 & 1 & 0.04 & & 1451 & & & & & 1451 & \\
\hline BIS058 & 3 & 0.04 & & 1536 & & & & & 1531 & \\
\hline BIS058 & 4 & 0.03 & & 1330 & & & & & 1330 & \\
\hline BIS059 & 2 & 0.22 & 2360 & 2375 & 44 & 95 & $\begin{array}{c}\text { Multiple slip } \\
\text { events }\end{array}$ & 2346 & 2348 & \\
\hline BIS059 & 3 & 0.19 & 2350 & 2359 & 46 & 85 & $\begin{array}{c}\text { Multiple slip } \\
\text { events }\end{array}$ & 2335 & 2343 & \\
\hline BIS059 & 4 & 0.17 & 2337 & 2340 & 49 & 74 & $\begin{array}{l}\text { Multiple slip } \\
\text { events }\end{array}$ & 2317 & 2319 & \\
\hline BIS059 & 5 & 0.16 & 2324 & 2326 & 52 & 66 & $\begin{array}{c}\text { Multiple slip } \\
\text { events }\end{array}$ & 2299 & 2302 & \\
\hline BIS059 & 6 & 0.15 & 2312 & 2313 & 55 & 59 & $\begin{array}{c}\text { Multiple slip } \\
\text { events }\end{array}$ & 2274 & 2279 & \\
\hline BIS060 & 1 & 0.03 & & 1531 & & & & & 1531 & \\
\hline BIS060 & 2 & 0.05 & & 1663 & & & & & 1661 & \\
\hline BIS060 & 3 & 0.16 & 2311 & 2311 & 62 & 56 & $\begin{array}{l}\text { Multiple slip } \\
\text { events }\end{array}$ & 2244 & 2256 & \\
\hline BIS060 & 4 & 0.12 & & 2142 & & & & & 2119 & \\
\hline BIS060 & 6 & 0.08 & & 1904 & & & & & 1899 & \\
\hline BIS060 & 7 & 0.09 & & 1989 & & & & & 1980 & \\
\hline BIS060 & 8 & 0.08 & & 1951 & & & & & 1944 & \\
\hline
\end{tabular}

${ }^{\mathrm{a}}$ Weakening is assumed to occur at the onset of viscous shear.

marked by the onset of viscous shear are included in Table 4. We estimate the weakening distance to be an average of $47 \mu \mathrm{m}$, with varying amounts of slip (up to $177 \mu \mathrm{m}$ ) being accommodated via viscous shear.

\section{Discussion}

\subsection{Comparison Between Microstructures and Models}

Evidence of a heterogeneously distributed glass film on the surface of faults slipped during episodic fast slip events (occurring where slip velocity is greater than the load point velocity) suggests that these regions form as a result of melting at localized, frictionally heated asperity contacts. Larger slip distances and higher sliding velocities are associated with an increase in the number and diameter of melted asperity contacts. The 

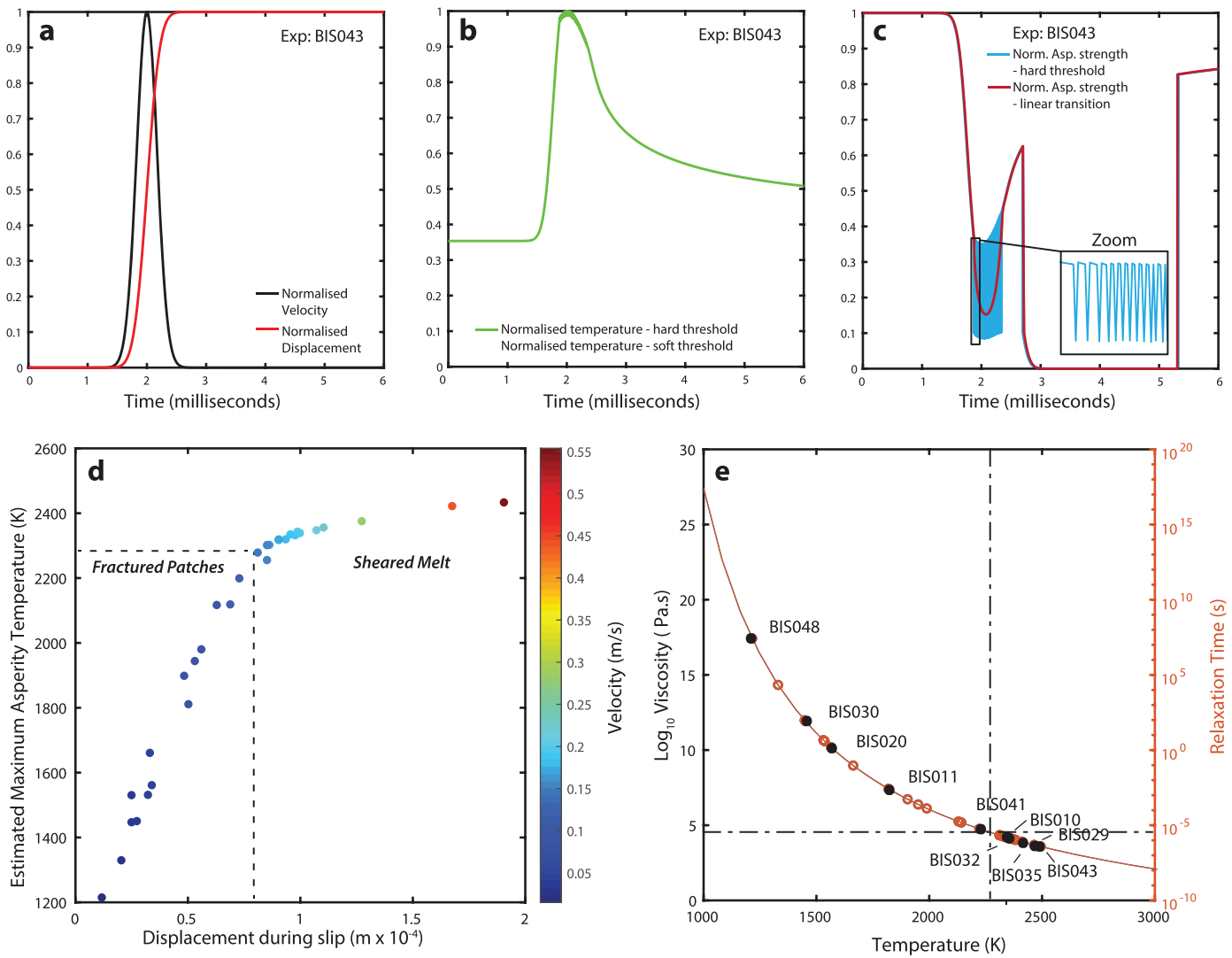

Figure 10. Modeling of asperity temperature, strength, and rheology. Model parameters and outputs: (a) slipdisplacement and velocity, (b) temperature estimated at the fault core (note: the elevated temperature prior to slip reflects an ambient temperature of $650{ }^{\circ} \mathrm{C}$ for this experiment), (c) estimated asperity strength using both hard and soft thresholding in the transition from frictional sliding to viscous shear. Data has been normalized against the maximum value. (d) Modeled asperity temperatures as a function of displacement occurring during rapid slip. Dashed lines indicate conditions at the microstructural transition between fractured patches and sheared melt textures. Data points are colored to show slip velocity. (e) Curve indicates viscosity and relaxation time for silica glass as a function of temperature. Experimental data are plotted using the maximum asperity temperature calculated by the thermal modeling. Lines indicate the conditions where relaxation time is short enough to allow viscous shear within the melt layer. Experiments in frictional sliding zone are microstructurally characterized by fractured glass patches, while experiments in viscous shear regime have sheared melt textures.

increase in contact area is consistent with asperities behaving both elastically and viscously as a result of melting. With increasing normal stress or a temperature-dependent decrease in asperity strength (including as a result of melt shear), asperities deform and flatten, increasing their size and contact area.

As the sliding velocity approaches a threshold of $\sim 0.15 \mathrm{~m} / \mathrm{s}$ the morphology of the melted regions changes from the debris-free patches formed by the fracture and spalling of locally heated and melted asperity tips to being characterized by sheared melt textures. Modeled behavior of asperities (i.e., frictional sliding versus viscous shear), based on the viscoelastic properties of the glass and maximum estimated asperity temperatures, are in good agreement with the microstructural observations. We find that the theoretical maximum displacement accommodated by viscous shear, based on our modeling, is within $5 \%$ of the microstructural observation of the maximum length of continuous sheared textures on the fault surfaces (Table 4). However, there are also a number of discrepancies between microstructural observations and model results that are worthy of discussion.

First, the estimated maximum asperity temperatures for a number of the smallest slip events (stress drop $<35$ $\mathrm{MPa}$ ) are too low to reach the minimum melting temperature of $\beta$-quartz ( $1673 \mathrm{~K}$, Ainslie et al., 1961), yet TEM analysis confirms the presence of partially melted asperity contacts. It is suggested that this inconsistency is due the conservative estimate of velocity that is used as an input for the temperature model. 
Additionally, for small slip events (stress drop $<50 \mathrm{MPa}$ ), the displacement occurring during the fast slip is less easily resolved. Increasing apparatus attenuation and a decreasing ratio of the amplitude of slip event compared with the apparatus response, leads to greater uncertainty in the modeled asperity temperatures.

Second, there is limited microstructural evidence for comminution or brittle wear on the surface of asperities where our model suggests behavior should be dominated by brittle-frictional sliding. Glass patches are rimmed by extensive fracturing aligned perpendicular to the slip direction. Fracture density is highest on the trailing edges of patches creating slivers of gouge around the margin. The geometry of these fractures is consistent with a sliding Hertzian contact (Bower \& Fleck, 1994; Hills et al., 1994) and consequently are thought to form dynamically by the brittle interaction of the glassy patch with an adjacent asperity contact during slip. At the leading edge and center of melt patches, fractures form parallel to the fault surface. The absence of gouge fragments or evidence for brittle wear (other than occasional cylindrical rolls), suggests that fault-parallel fractures are unlikely to be associated with the dynamic fault motion. Our modeling suggests that when velocity decreases at the end of slip, the glass transition is crossed allowing viscous mobilization in samples where slip velocities prevent viscous shear during slip. This post-slip viscous behavior may allow small aperture brittle fractures to heal and welds to form at abutting asperity contacts. These welds potentially fracture parallel to the fault surface as a result of thermal spalling, unloading or during sample preparation. However, at this stage we are unable to distinguish between microstructures formed during primary melting and those potentially formed during viscous remobilization late during a fast slip event.

Finally, the widths of the melt zones are inconsistent with estimated temperatures if we were to assume a minimum melting temperature for quartz at room pressure. The models suggest that temperatures $>2310$ $\mathrm{K}$ are required to achieve a viscosity low enough and relaxation times short enough to accommodate shear within the $1 \mu \mathrm{m}$ wide melt layer at the velocities estimated from our experiments. Microstructural observations suggest that the melted zone is generally $1-2 \mu \mathrm{m}$ wide on faults where the reactivation angle, $\theta_{r}=30^{\circ}$ (e.g., Figure 6). If parameters controlling diffusion of heat in quartz (e.g., thermal conductivity, specific heat capacity, and density), are largely unaffected by changes in pressure, a melt width of 1-2 $\mu \mathrm{m}$ is consistent with a melting temperature of $\sim 2275 \mathrm{~K}$ or equivalent to the melting temperature of quartz at $\sim 1.4 \mathrm{GPa}$ (Hudon et al., 2002). If we were to assume room pressure melting temperatures, the width of the melted zone should be significantly wider (i.e., in the order of $\sim 30-40 \mu \mathrm{m}$ ). Given that many previous studies use the onset of melting as an indicator of the onset of weakening (Chen \& Rempel, 2014; Rempel \& Weaver, 2008; Rice, 1999, 2006, 2017), our results suggest that if asperity pressures are not considered in estimating melting temperatures, then there is potential for overestimation of the onset and duration of weakening attributable to viscous shear.

\subsection{Strength of a Population of Asperities}

In discussions above we consider the maximum possible duration of a single asperity contact for a given slip event. However, the roughness of natural fault surfaces suggests that asperities occur on a scale that spans several orders of magnitude (Power \& Tullis, 1992). Consequently, the behavior of a single asperity may not be reflective of the behavior of the entire fault surface. Despite this observation, many previous studies consider only a single "representative" asperity (Chen \& Rempel, 2014; Rempel \& Weaver, 2008), although Beeler et al. (2008) showed that using a distribution of asperity sizes modified the predicted flash weakening behavior by smoothing the initial rapid variation in frictional strength once the weakening velocity was exceeded. In the following section, we consider the strength of a population of asperities to determine how a range of asperity sizes influences the critical distance and temperature at the onset of weakening. We assume that the average asperity strength is proportional to overall frictional resistance of the fault (Rempel \& Weaver, 2008).

The evolution of the contact areas during slip is complex, and to understand bulk fault strength to first order, we model a population of random asperities over the lifetime of the slip event. For each asperity in our population, its diameter is randomly sampled with a mean of $100 \mu \mathrm{m}$ and a standard deviation of $30 \mu \mathrm{m}$ where these numbers are estimated from the microstructural results and we assume a Gaussian distribution based on the observations of Brown and Scholz (1985). An asperity is deemed to have lost contact if the total slip has passed the right edge of an asperity. Once this occurs, a new asperity is generated with ambient temperature and a new random diameter with its left edge coincident with the right edge of the previous asperity (Figure 11a). This ensures that a constant number of asperities is in contact during simulated slip but are, 

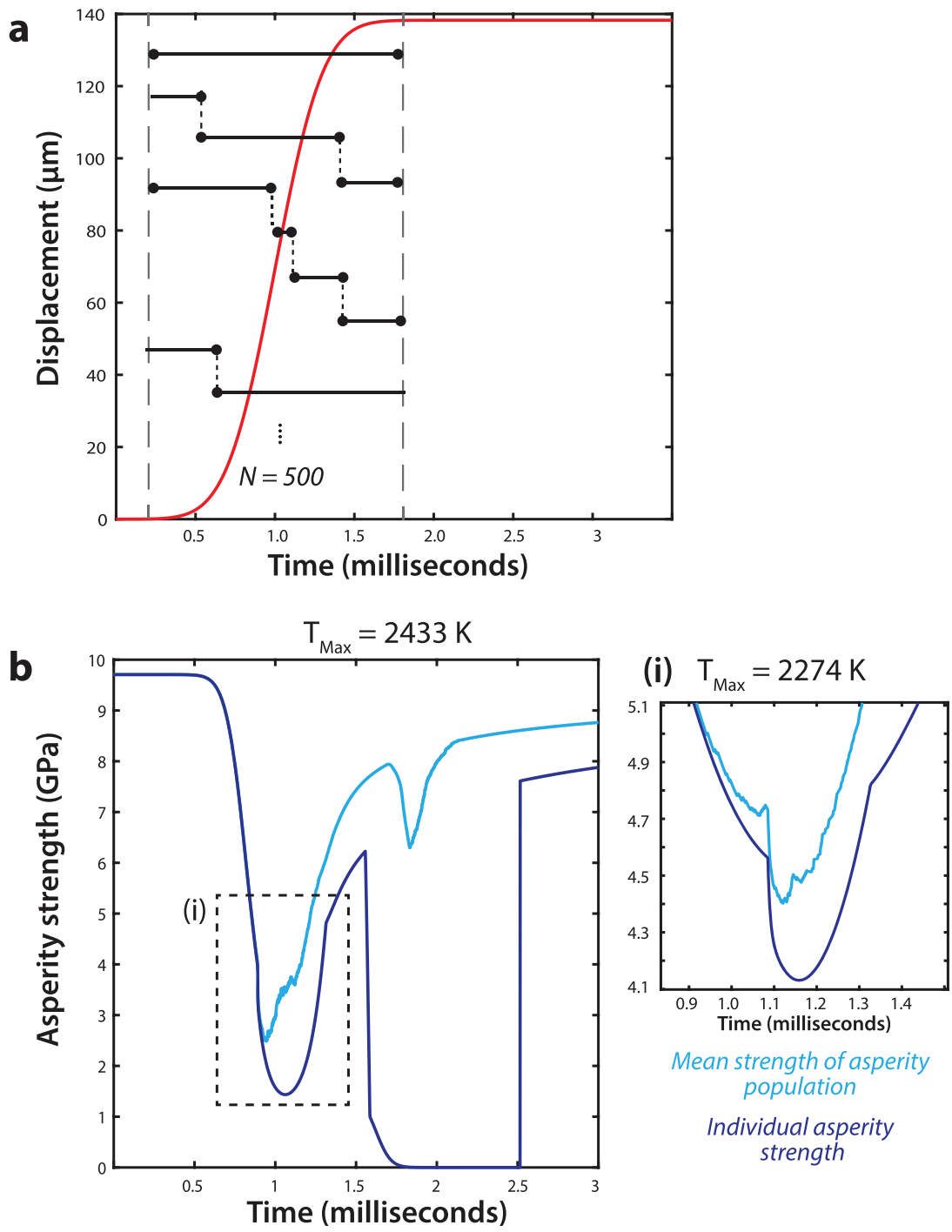

Figure 11. Mean strength and weakening of asperity population during slip. (a) Fault displacement is shown by the red curve. A population of 500 randomly sized asperities (mean diameter $100 \mu \mathrm{m}$ ) with normal distribution is modeled. Asperity contact times are represented by the black lines. At the moment when an asperity is no longer in contact a new asperity is created, ensuring that the same number of asperities are always in contact. Mean strength of asperities is calculated at each time step in the model. (b) Comparison of individual asperity strength and the mean strength of a population of asperities for a large slip event $\left(T_{\max }=2525 \mathrm{~K}\right)$. Mean strength of the asperity population shows that weakening is not as efficient on the population of asperities either during or following slip. (i) Zoom of the transition to viscous shear in a smaller slip event, where the $T_{\max }$ is just high enough to allow the transition to viscous shear. Sliding on new, cooler, and stronger asperities reduces weakening. However, the strengthening effect of slip on new asperities causes minimal delay in the transition to viscous shear.

in general, at different stages of weakening. A 1-D heat simulation is run for each asperity using the above specified asperity geometry. Average asperity strength is then calculated at each time step in the model, assuming that only asperities in contact contribute to the mean instantaneous strength of the fault.

A comparison of the maximum individual asperity strength and the average strength based on a population of asperities shows that the onset of thermally induced asperity softening is identical for both (Figure 11b), as is the slip distance until the onset of viscous sliding. However, the magnitude of weakening associated with viscous shear is reduced for the population of asperities and fault restrengthening occurs more rapidly. Although, this result is logical given that average strength is influenced by the number of weakened asperities in contact at any given point, it suggests that modeling fault behavior based on a single representative asperity may result in an overestimation of the extent and duration of viscous-shear-related weakening. 
Once the strain rate decreases at the cessation of fast slip and new asperities no longer come into contact, melted asperities can transition from frictional sliding to being a viscous melt. For individual asperity this transition occurs abruptly, whereas for the population of asperities, postslip weakening is reduced both in magnitude and duration. The occurrence of postseismic weakening, its efficiency and duration are strongly dependent on the ambient temperature of the fault, with a greater likelihood of viscous behavior at high ambient temperatures.

\subsection{Fault Weakening}

Although dynamic weakening mechanisms, such as flash heating, do not contribute to the initiation of fault rupture, they are important for the continuation of slip momentum, and at a crustal scale, for the generation of large earthquakes (Nielsen, 2017; Noda et al., 2011). In the previous section we show that rapid weakening occurs at the onset of viscous shear, based on the assumption that the average strength of a population of asperities is proportional the macroscopic friction on the fault (Rempel \& Weaver, 2008). In this section we test this assumption by comparing nucleation of events initiating with the same frictional strength and elastic potential energy.

For experiments where all aspects of fault geometry and loading conditions are the same, peak shear stress is proportional to both the frictional strength and the elastic potential energy. Elastic potential energy accumulated during loading is stored through elastic deformation of the apparatus loading frame, assembly, and sample and is released as kinetic energy during the slip event. Under comparable conditions we find significant variation in the size of events and the velocity of slip. Shear displacement varies from $\sim 55-132 \mu \mathrm{m}$, stress drops range from $\sim 31-75 \mathrm{MPa}$, and slip occurs at velocities between 3 and $16 \mathrm{~cm} / \mathrm{s}$ (Figure 12a). Mean asperity strength of an asperity population is shown in Figure $12 \mathrm{~b}$ for each of the events. Increasing event size (Figure 12a) correlates with increasing slip velocity and therefore decreasing minimum asperity strength. Not all slip events transition to viscous shear during slip, which is consistent with microstructural observations. Importantly, there is a progressive linear increase in stress drop with increasing shear slip, suggesting more than one weakening mechanism (i.e., weakening occurs before the activation of the transition to viscous shear). Using the temperature-dependent asperity strength (Figure 3c), we have modeled both a thermally induced softening of asperities and the transition from brittle-frictional behavior to viscous shear. Model results are in good agreement with the experimental observations.

\subsection{Implications}

From a modeling perspective, the formation of melt on a fault surface is commonly thought to be accompanied by a transition from high-strength frictional sliding to a low-strength viscous shear (Chen \& Rempel, 2014; Rempel \& Weaver, 2008; Rice, 2017). The strength of the melted interface, in turn, is modeled as being equivalent to the Newtonian viscosities of the melts produced (Chen \& Rempel, 2014; Rempel \& Weaver, 2008). Although these assumptions provide useful first order results, this approach does not address the complexities of strain-rate-dependent behavior of the melt at asperity contacts nor address experimental observations that in some situations the onset of melting is associated with a transient strengthening (Koizumi et al., 2004; Tsutsumi \& Shimamoto, 1997).

Our results show that the rheology of the melt formed at the asperity tips during seismic slip plays an important role in the behavior and strength of asperities. Data suggest that asperities do not transition from brittle frictional contacts to viscously shearing contacts at the onset of melting. Rather, the viscoelastic properties of the melt and the slip rate determine the strength and behavior of the asperities. An important consequence of this distinction is that asperity tips, which microstructurally show a surface layer of melt, may still deform in the brittle domain rather than shearing viscously (i.e., $\dot{\varepsilon}(t)>\dot{\varepsilon}_{g}(t)$ ). If they remain in the brittle field, they are potential sources for generating further frictional heat. As the melt at asperity tips forms narrow layers ( $<1-2 \mu \mathrm{m}$ thick), high temperatures (well above the room pressure melting temperatures) are required to reduce viscosity and allow the transition to viscous shear (i.e., cross the glass transition). Consequently, the presence of amorphous material (whether thermally melted, or amorphization occurs as a result of mechanical action or pressure) is not synonymous with weakening on the fault.

At the larger scale, when fault rupture results in the transition from flash heating to a full melt layer, melt rheology still plays an important role in the behavioral response of the melt to shearing (Lavallee et al., 2015). However, as the melt zone widens, the strain rate decreases with shear being accommodated across 
a

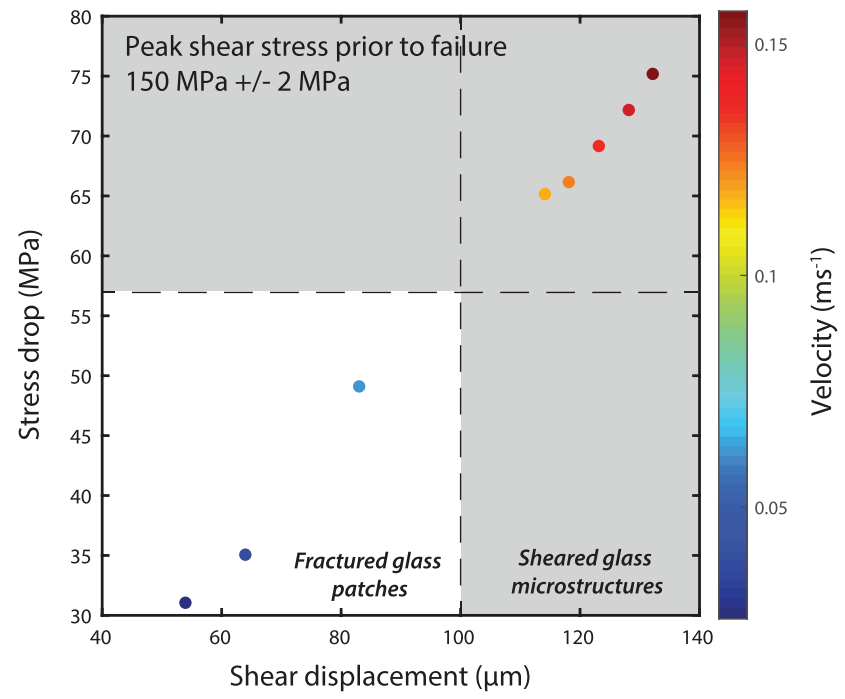

b

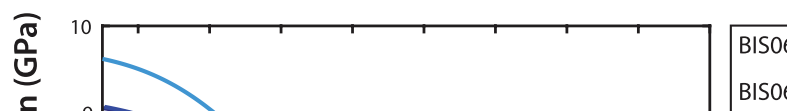

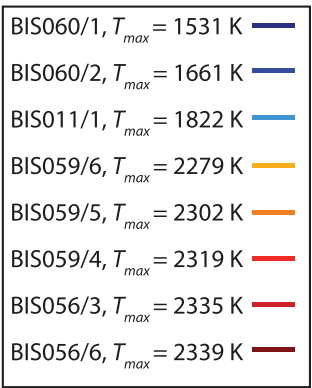

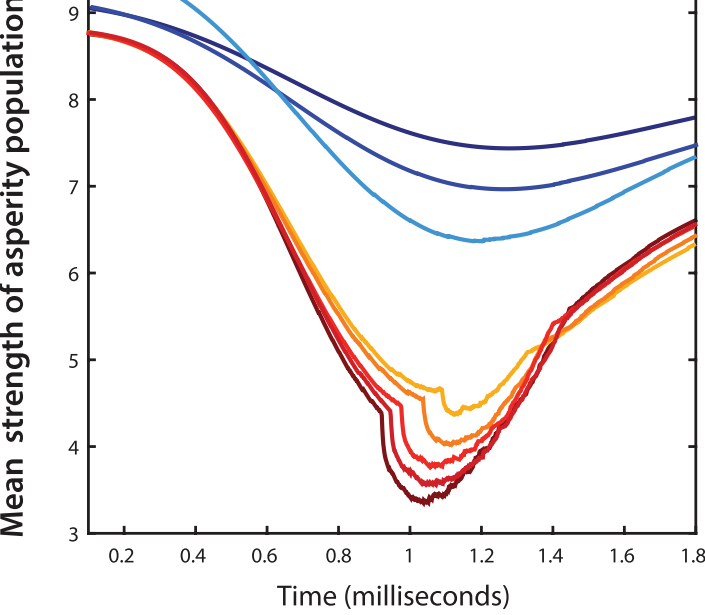

है
$\frac{0}{4}$

Figure 12. Dynamic weakening of asperity population during slip. (a) Relationship between stress drop and shear displacement for a number of slip events where rupture nucleated at an equivalent peak shear stress. Data points are color coded to indicate maximum slip velocity. (b) Mean asperity strength for a population of asperities for each slip event shown in (a). Strength curves in (b) color match data points in (a). Modeled results suggest agreement with microstructural observations; only events having sheared glass microstructures transition to viscous shear in our model. The different strength values prior to the commencement of slip represent different experimental ambient temperatures.

a thicker zone. Consequently, a melted layer would be able to viscously accommodate higher slip rates at potentially lower melt temperatures.

\section{Conclusions}

Triaxial stick-slip experiments performed over a range of normal stresses and differing ambient temperatures on Fontainebleau sandstone provide unequivocal evidence for the effects of frictional heating on asperity contacts. We document a microstructural evolution of asperity interactions from the onset of flash heating through to the formation of grain-scale areas of sheared melt. We show a change in the morphology of the frictionally melted asperity contacts with increasing slip velocity and modeled asperity temperature. Asperity contacts transition from fractured glass patches to being characterized by viscously sheared melt. Using these observations and mechanical inputs from the experiments we have modeled temperature and the viscoelastic behavior of the glass, assuming a non-Newtonian, strain-rate dependent viscosity. Our 
results show that the fractured patches coincide with low modeled asperity temperatures, and we conclude that the slip rates and temperatures for these experiments preclude the melted asperity contacts from crossing the glass transition and as such they behave as a glassy solid. Fault surfaces with sheared melt textures are predicted to have transitioned from brittle-frictional behavior to viscous shear and occur in experiments where $v_{\text {slip }}>0.15 \mathrm{~m} / \mathrm{s}$. Weakening distances, estimated to occur at the glass transition, have been calculated to be $\sim 47 \mu \mathrm{m}$, occurring when temperatures reach $\sim 2370 \mathrm{~K}$, assuming strain is accommodated in a $1 \mu \mathrm{m}$ thick layer. We conclude that it is highly likely that asperities melt at pressure-induced melting temperatures, with many asperities likely melting at around $1.4 \mathrm{GPa}$, with a melting temperature of $\sim 2275 \mathrm{~K}$. However, it is possible that if contact pressure decreases during ongoing slip (e.g., by asperities separating, being destroyed), adiabatic melting could occur upon depressurization. The strain rate dependence of glass relaxation implies that postslip melt mobilization may occur, although at very low strain rates, potentially allowing fractures to heal and welds to form.

The behavior of the average fault strength has been modeled using asperity populations. We find that, compared with an individual asperity, time to the onset of weakening is similar to the single asperity model, although the magnitude and duration of weakening is reduced. We show that increasing average asperity temperature results in a progressive decrease in overall fault strength, supporting the idea that flash heating resulting from the shear of melted asperity contacts is a potential mechanism for dynamic weakening. However, we also note that progressive weakening occurs, even in samples which do not transition to viscous shear, suggesting the activation of more than one temperature-dependent mechanism. We model weakening occurring as a result of both thermal softening of asperities and from the transition from brittle-frictional behavior to viscous shear. We conclude that during the extreme conditions associated with earthquake slip, the strength, behavior, and rheology of both the crystalline fault components and their melted counterparts need to be considered. This will require a reassessment of flash heating models to allow the incorporation of viscoelastic melt behavior. Finally, this study points to the need for future experimental work to constrain the physical properties of melts at the extreme conditions occurring on fault surfaces during seismic slip. This will allow a more rigorous understanding of pseudotachylyte strength and behavior and its influence on controlling fault weakening.

\section{Acknowledgments}

L. Li from the Australian National Fabrication Facility (ANFF) and H. Miller and H. Kokkonen from the Research School of Earth Sciences are thanked for their technical support. A. Schubnel generously provided the Fontainebleau sandstone used in this project. M. Drury, G. Pennock, and R. Heilbronner are thanked for their interesting and relevant discussions. Electron Microscopy work was undertaken at the Australian National Centre for Advanced Microscopy. FIB sections were prepared at the Australian Capital Territory Node of the ANFF. John FitzGerald is thanked for his assistance with the transmission electron microscopy. This study was supported by Australian Research Council Discovery Grant DP1301102587 and Australian National University 2016 Major Equipment Grant. K. Hayward gratefully acknowledges scholarship support from the Australian Government Research Training Program and Research Schoo of Earth Sciences. Two anonymous reviewers and the Associate Editor are thanked for their insightful comments which added greatly to the clarity of the manuscript. Data presented in this paper are available for download from the ANU Data Commons website (https://datacommons.anu.edu.au/ DataCommons/) or at (https://dx.doi. org/10.25911/5dcb3e4b6a171).

\section{References}

Ainslie, N. G., Mackenzie, J. D., \& Turnbull, D. (1961). The Melting Kinetics of Quartz and Cristobalite. The Journal of Physical Chemistry, 65(10), 1718-1724. https://doi.org/10.1021/j100827a012

Aki, K. (1984). Asperities, barriers, characteristic earthquakes and strong motion predition. Journal of Geophysical Research, 89(B7), 5867-5872. https://doi.org/10.1029/JB089iB07p05867

Aubry, J., Passelégue, F. X., Deldicque, D., Girault, F., Marty, S., Lahfid, A., et al. (2018). Freictional heating processes and energy budget during laboratory earthquakes. Geophysical Research Letters, 45, 12,274-12,282. https://doi.org/10.1029/2018GL079263

Beeler, N. M., Tullis, T. E., \& Goldsby, D. L. (2008). Constitutive relationships and physical basis of fault strength due to flash heating. Journal of Geophysical Research, 113, B01401. https://doi.org/10.1029/2007JB004988

Bottinga, Y., \& Richet, P. (1996). Silicate melt structural relaxation: rheology, kinetics, and Adam-Gibbs theory. Chemical Geology, 128(1-4), 129-141. https://doi.org/10.1016/009-2541(95)00168-9

Bourova, E., \& Richet, P. (1998). Quartz and cristobalite: High-temperature cell parameters and volumes of fusion. Geophysical Research Letters, 25(13), 2333-2336. https://doi.org/10.1029/98GL01581

Bower, A. F., \& Fleck, N. A. (1994). Brittle fracture under a sliding line contact. Journal of the Mechanics and Physics of Solids, 42(9), 1375-1396. https://doi.org/10.1016/0022-5096(94)90002-7

Brace, W. F., \& Byerlee, J. D. (1966). Stick-slip as a mechanism for earthquakes. Science, 153(3739), 990-992. https://doi.org/10.1126/ science.153.3739.990

Branlund, J. M., \& Hofmeister, A. M. (2007). Thermal diffusivity of quartz to $1000^{\circ} \mathrm{C}$ : effects of impurities and the alpha-beta phase transition. Physics and Chemistry of Minerals, 34(8), 581-595. https://doi.org/10.1007/s00269-007-0173-7

Brodsky, E. E., \& Kanamori, H. (2001). Elastohydrodynamic lubrication of faults. Journal of Geophysical Research, 106(B8), 16,357-16,374. https://doi.org/10.1029/2001JB000430

Brown, K. M., \& Fialko, Y. (2012). 'Melt welt' mechanism of extreme weakening of gabbro at seismic slip rates. Nature, 488(7413), 638-641. https://doi.org/10.1038/nature11370

Brown, S. R., \& Scholz, C. (1985). Closure of random elastic surfaces in contact. Journal of Geophysical Research, 90(B7), 5531-5545. https:// doi.org/10.1029/JB09iB07p05531

Brune, J., Henyey, T., \& Roy, R. (1969). Heat flow, stress and rate of slip along the San Andreas Fault, California. Journal of Geophysical Research, 74(15), 3821-3827. https://doi.org/10.1029/JB074i015p03821

Byerlee, J. D. (1978). Friction of rocks. Pure and Applied Geophysics, 116, 615-626. https://doi.org/10.1007/BF00876528

Chen, J., \& Rempel, A. W. (2014). Progressive flash heating and the evolution of high-velocity rock friction. Journal of Geophysical Research: Solid Earth, 119, 3182-3200. https://doi.org/10.1002/2013JB010631

Cohen, A., Daubechies, I., \& Feauveau, J.-C. (1992). Biorthogonal bases of compactly supported wavelets. Communications on Pure and Applied Mathematics, 45(5), 485-560. https://doi.org/10.1002/cpa.3160450502 
Courant, R., Friedrichs, K., \& Lewy, H. (1967). On the partial difference equations of mathematical physics. IBM Journal of Research and Development, 11(2), 215-234. https://doi.org/10.1147/rd.112.0215

Crank, J., \& Nicolson, P. (1947). A practical method for numerical evaluation of solutions of partial differential equations of the heat conduction type. Proceedings of the Cambridge Philosophical Society, 43(1), 50-67. https://doi.org/10.1017/S0305004100023197

Dash, J. G. (2002). Melting from one to two to three dimensions. Contemporary Physics, 43(6), 427-436. https://doi.org/10.1080/ 00107510210151763

Dell'Angelo, L. N., \& Tullis, J. (1988). Experimental deformation of partially melted granitic aggregates. Journal of Metamorphic Geology, 6(4), 495-515. https://doi.org/10.1111/j.1525-1314.1988.tb00436.x

Di Toro, G., Goldsby, D. L., \& Tullis, T. E. (2004). Friction falls towards zero in quartz rock as slip velocity approaches seismic rates. Nature, 427(6973), 436-439. https://doi.org/10.1038/nature02249

Di Toro, G., Hirose, T., Nielsen, S., Pennacchioni, G., \& Shimamoto, T. (2006). Natural and experimental evidence of melt lubrication of faults during earthquakes. Science, 311, 647-649. https://doi.org/10.1126/science.1121012

Di Toro, G., Niemeijer, A., Nielsen, S., Di Delice, F., Scarlato, P., Spada, G., et al. (2010). From field geology to earthquake simulation: a new state-of-the-art tool to investigate rock friction during the seismic cycle (SHIVA). Rendiconti Lincei, 21(1), 95-114. https://doi.org/ 10.1007/s12210-010-0097-x

Di Toro, G., \& Pennacchioni, G. (2005). Fault plane processes and mesoscopic structure of a strong-type seismogenic fault in tonalites (Adamello batholith, Southern Alps). Tectonophysics, 402(1-4), 55-80. https://doi.org/10.1016/j.tecto.2004.12.036

Dieterich, J. H., \& Kilgore, B. D. (1994). Direct observation of frictional contacts: New insights for state-dependent properties. Pageoph, 143(1/2/3), 283-302. https://doi.org/10.1007/BF00874332

Donoho, D. L., Johnstone, I. M., Kerkyacharian, G., \& Picard, D. (1995). Wavelet Shrinkage: Asymptopia? Journal of the Royal Statistical Society Series B (Methodological), 57(2), 301-369. https://doi.org/10.2307/2345967

Doremus, R. (2002). Viscosity of silica. Journal of Applied Physics, 92(12), 7619-7629. https://doi.org/10.1063/1.1515132

Evans, B. (1984). The effect of temperature and impurity content on the indentaion hardness of quartz. Journal of Geophysical Research, 89(B6), 4213-4222. https://doi.org/10.1029/JB089iB06p04213

Fialko, Y., \& Khazan, Y. (2005). Fusion by earthquake fault friction: stick or slip? Journal of Geophysical Research, 110, B12407. https://doi. org/10.1029/2005JB003869

Fujiwara, T., Kodaira, S., No, T., Kaiho, Y., Takahashi, N., \& Kaneda, Y. (2011). The 2011 Tohoku-Oki earthquake: displacement reaching the trench axis. Science, 334(6060), 1240. https://doi.org/10.1126/science.1211554

Gilbert, B., \& Mainprice, D. H. (2009). Effect of crystal perferred orientations on the thermal diffusivity of quartz polycrystalline aggregates at high temperature. Tectonophysics, 465, 150-163. https://doi.org/10.1016/j.techto.2008.11.006

Goldsby, D. L., \& Tullis, T. E. (2002). Low frictional strength of quartz rocks at subseismic slip rates. Geophysical Research Letters, 29(17), 1844. https://doi.org/10.1029/2002GL015240

Goldsby, D. L., \& Tullis, T. E. (2011). Flash heating leads to low frictional strength of crustal rocks at earthquake slip rates. Science, 334(6053), 216-218. https://doi.org/10.1126/science.1207902

Greenwood, J. A., \& Williamson, J. B. P. (1966). Contact of nominally flat surfaces. Proceedings of the Royal Society of London, A295, 300-319. https://doi.org/10.1098/rspa.1966.0242

Han, R., Hirose, T., \& Shimamoto, T. (2010). Strong velocity weakening and powder luüication of simulated carbonate faults at seismic slip rates. Journal of Geophysical Research, 115, B03412. https://doi.org/10.1029/2008JB006136

Han, R., Shimamoto, T., Hirose, T., Ree, J., \& Ando, J. (2007). Ultralow fricton of carbonate faults caused by thermal decomposition. Science, 316(5826), 878-881. https://doi.org/10.1126/science.1139763

Harbord, C. W. A., Nielsen, S., De Paola, N., \& Holdsworth, R. E. (2017). Earthquake nucleation on rough faults. Geology, 45(10), 931-934. https://doi.org/10.1130/G39181.1

Hayashi, N., \& Tsutsumi, A. (2010). Deformation textures and mechanical behavior of a hydrated amorphous silica formed along an experimentally produced fault in chert. Geophysical Research Letters, 37, L12305. https://doi.org/10.1029/20100GL042943

Hayward, K. S., \& Cox, S. F. (2017). Melt welding and its role in fault reactivation and localization of fracture damage in seismically active faults. Journal of Geophysical Research: Solid Earth, 122, 1-25. https://doi.org/10.1002/2017JB014903

Hayward, K. S., Cox, S. F., Fitz Gerald, J., Slagmolen, B., Shaddock, D., Forsyth, P., et al. (2016). Mechanical amorphisation, flash heating and frictional melting: dramatic changes to fault surfaces during the first millisecond of earthquake slip. Geology, 44(12), 1043-1046. https://doi.org/10.1130/G38242.1

Hills, D. A., Munisamy, R. L., \& Nowell, D. (1994). Brittle Fracture from a sliding Hertzian contact. Journal of Mechanical Engineering Science, 208(6), 409-415. https://doi.org/10.1243/PIME_PROC_1994_208_146_02

Hirose, T., \& Shimamoto, T. (2005). Growth of molten zone as a mechanism of slip weakening of simulated faults in gabbro during frictional melting. Journal of Geophysical Research, 110, B05202. https://doi.org/10.1029/2004JB003207

Hudon, P., Jung, I., \& Baker, D. R. (2002). Melting of $\beta$-quartz up to 2.0GPa and thermodynamic optimization of the silica liquidus up to 6.0 GPa. Physics of the Earth and Planetary Interiors, 130, 159-174. https://doi.org/10.1016/S0031-9201(02)00005-5

Jaeger, J. C. (1942). Moving sources of heat and the temperature of sliding contacts. Proceedings of the Royal Society NSW, 76, 203-224. https://doi.org/10.1115/1.2927035

Johnston, M. J. S., Borcherdt, R. D., Linde, A. T., \& Gladwin, M. T. (2006). Continuous borehole strain and pore pressure in the near field of the 28 September 2004 M 6.0 Parkfield, California, Earthquake: implications for nucleation, fault response, earthquake predition and tremor. Bulletin of the Seismological Society of America, 96(4B), S56-S72. https://doi.org/10.1785/ 0120050822

Koizumi, Y., Otsuki, K., Takeuchi, A., Takeuchi, A., \& Nagahama, H. (2004). Frictional melting can terminate seismic slips: Experimental results of stick-slips. Geophysical Research Letters, 31, L21605. https://doi.org/10.1029/2004GL020642

Kowitz, A., Güldemeister, N., Reimold, W., Schmitt, R. T., \& Wünnemann, K. (2013). Diaplectic quartz glass and SiO2 melt experimentally generated at only $5 \mathrm{GPa}$ shock pressure in porous sandstone: Laboratory observations and meso-scale numerical modeling. Earth and Planetary Science Letters, 384, 17-26. https://doi.org/10.1016/j.epsl.2013.09.021

Lachenbruch, A., \& Sass, J. (1980). Heat flow and energetics of the San Andreas Fault Zone. Journal of Geophysical Research, 85(B11), 6185-6222. https://doi.org/10.1029/JB085iB11p06185

Lachenbruch, A. H. (1980). Frictional heating, fluid pressure and the resistance to fault motion. Journal of Geophysical Research, 85(B11), 6097-6112. https://doi.org/10.1029/JB085iB11p06097

Lakshtanov, D. L., Sinogeikin, S. V., \& Bass, J. D. (2006). High-temperature phase transitions and elasticity of silica polymorphs. Physics and Chemistry of Minerals, 34(1), 11-22. https://doi.org/10.1007/s00269-006-0113-y 
Lavallee, Y., Hirose, T., Kendrick, J., Hess, K. U., \& Dingwell, D. B. (2015). Fault rheology beyond frictional melting. Proceedings of the National Academy of Sciences of the United States of America, 112(30), 9276-9280. https://doi.org/10.1073/pnas.1413608112

Lay, T., \& Kanamori, H. (1981). An asperity model of large earthquake sequences. In Earthquake Prediction - An International Review, (pp. 579-592). Washington, DC: American Geophysical Union. https://doi.org/10.1029/ME004P0579

Lockner, D. A., \& Byerlee, J. D. (1986). Laboratory measurements of velocity-dependent frictional strength. US Geological Survey Open File Report, 86-417, 1-55. https://doi.org/10.3133/ofr86417

Lockner, D. A., Kilgore, B.D., Kilgore, N. M., \& Moore, D. E. (2017). The transition from frictional sliding to shear melting in laboratory stick-slip experiments. Fault zone dynamic processes: Evolution of fault properties during seismic rupture, 105-132.

Logan, J. M., \& Teufel, L. W. (1986). The Effect of Normal Stress on the Real Area of Contact During Frictional Sliding in Rocks. Pageoph, 124(3), 471-485. https://doi.org/10.1007/BF00877212

Ma, S., Shimamoto, T., Yao, L., Togo, T., \& Kitajima, H. (2014). A rotary-shear low to high-velocity friction apparatus in Beijing to study rock friction at plate to seismic slip rates. Earthquake Science, 27(5), 469-497. https://doi.org/10.1007/s11589-014-0097-5

Malagnini, L., Nielsen, S., Mayeda, K., \& Boshi, E. (2010). Energy radiation from intermediate- to large- magnitude earthquakes: Implications for dynamic fault weakening. Journal of Geophysical Research, 115, B06319. https://doi.org/10.1029/2009JB006786

Mase, C. W., \& Smith, L. (1987). Effects of frictional heating on the thermal, hydrologic and mechanical response of a fault. Journal of Geophysical Research, 92(B7), 6249-6272. https://doi.org/10.1029/JB092iB07p06249

Maxwell, J. C. (1867). On the dynamical theory of gases. Philosophical Transactions of the Royal Society, 157, 49-88. https://doi.org/10.1098/ rstl.1867.0004

McKenzie, D., \& Brune, J. N. (1972). Melting on fault planes during large earthquakes. Geophysical Journal International, 29(1), 65-78. https://doi.org/10.1111/j.1365-246X.1972.tb06152.x

Mei, Q. S., \& Lu, K. (2007). Melting and superheating of crystalline solids: From bulk to nanocrystals. Progress in Materials Science, 52(8), 1175-1262. https://doi.org/10.1016/j.pmatsci.2007.01.001

Mitchell, E. K., Fialko, Y., \& Brown, K. M. (2016). Velocity-weakening behavior of Westerly granite at temperature up to $600{ }^{\circ} \mathrm{C}$. Journal of Geophysical Research: Solid Earth, 121, 6932-6946. https://doi.org/10.1002/2016JB013081

Nakamura, Y., Muto, J., Nagahama, H., Shimizu, I., Miura, T., \& Arakawa, I. (2012). Amorphization of quartz by friction: Implication to silica-gel lubrication of fault surfaces. Geophysical Research Letters, 39, L21303. https://doi.org/10.1029/2012GL053228

Narayanaswamy, O. S. (1971). A Model of structural relaxation in glass. Journal of the American Ceramic Society, 54(10), 491-498. https:// doi.org/10.1111/j.1151-2916.1971.tb12186.x

Nielsen, S. (2017). From slow to fast faulting: recent challenges in earthquake fault mechanics. Philosophical Transactions of the Royal Society of London: Series A, Mathematical and Physical Sciences, 375(2103). https://doi.org/10.1098/rsta.2016.0016

Nielsen, S., Di Toro, G., \& Griffith, W. A. (2010). Friction and roughness of a melting rock surface. Geophysical Journal International, 182, 299-310. https://doi.org/10.1111/j.1365-246X.2010.04607.x

Niemeijer, A., Di Toro, G., Griffith, W. A., Bistacchi, A., Smith, L., \& Nielsen, S. (2012). Inferring earthquake physics and chemistry using an integrated field and laboratory approach. Journal of Structural Geology, 39, 2-36. https://doi.org/10.1016/j.jsg.2012.02.018

Noda, H., Lapusta, N., \& Rice, J. R. (2011). Earthquake sequence calculations with dynamic weakening mechanisms. In R. I. Borja (Ed.), Multiscale and multiphysics processes in geomechanics (pp. 149-152). Berlin: Springer. https://doi.org/10.1007/978-3-64219630-0_38

Passelégue, F., Schubnel, A., Nielsen, S., Bhat, H., Deldicque, D., \& Madariaga, R. (2016). Dynamic rupture processes inferred from laboratory microearthquakes. Journal of Geophysical Research: Solid Earth, 121, 4343-4365. https://doi.org/10.1002/2015JB012694

Paterson, M. S. (1970). A high-pressure, high-temperature apparatus for rock deformation. International Journal of Rock Mechanics, Mining Sciences and Geomechanics, 7, 517-526. https://doi.org/10.1016/0148-9062(70)90004-5

Power, W. L., \& Tullis, T. E. (1992). The contact between opposing fault surfaces at Dixie Valley, Nevada, and implications for fault mechanics. Journal of Geophysical Research, 97(B11), 15,425-15,435. https://doi.org/10.1029/92JB01059

Proctor, B. P., Mitchell, T. M., Hirth, G., Goldsby, D. L., Zorzi, F., Platt, J. D., \& Di Toro, G. (2014). Dynamic weakening of serpentinite gouges and bare surfaces at seismic slip rates. Journal of Geophysical Research: Solid Earth, 119, 1-25. https://doi.org/10.1002/ 2014JB011057

Reches, Z., \& Lockner, D. A. (2010). Fault weakening and earthquake instability by powder lubrication. Nature, 467(7314), $452-455$. https://doi.org/10.1038/nature09348

Rekhson, S. M., Bulaeva, A. V., \& Mazurin, O. V. (1971). Changes in the linear dimensions and viscosity of window glass during stabilization. Inorganic Materials (Engl. Tran.), 7, 622-623.

Rempel, A. W., \& Rice, J. R. (2006). Thermal pressurization and onset of melting in fault zones. Journal of Geophysical Research, 111, B09314. https://doi.org/10.1029/2006JB004314

Rempel, A. W., \& Weaver, S. L. (2008). A model for flash weakening by asperity melting during high-speed earthquake slip. Journal of Geophysical Research, 113, B11308. https://doi.org/10.1029/2008JB005649

Rice, J. R. (1999). Flash heating at asperity contacts and rate-dependent friction. Eos, Transactions, American Geophysical Union, 80. 46, Fall Meet. Suppl.), F681 1

Rice, J. R. (2006). Heating and weakening of faults during earthquake slip. Journal of Geophysical Research, 111, B05311. https://doi.org/ 10.1029/2005JB004006

Rice, J. R. (2017). Heating, weakening and shear localization in earthquake rupture. Philosophical Transactions of the Royal Society of London: Series A, Mathematical and Physical Sciences, 275, 1-11. https://doi.org/10.1098/rsta.2016.0015

Richet, P., \& Bottinga, Y. (1984). Glass transitions and thermodynamic properties of amorphous $\mathrm{SiO}_{2}, \mathrm{NaALSi}_{\mathrm{n}} \mathrm{O}_{2} \mathrm{n}+2$ and $\mathrm{KAlSi}_{3} \mathrm{O}_{8}$. Geochemica et Cosmochimica Acta, 48, 453-470.

Richet, P., Bottinga, Y., Denielou, L., Petitet, J. P., \& Tequi, C. (1982). Thermodynamic properties of quartz, cristobalite and amorphous $\mathrm{SiO}_{2}$ : drop calorimetry measurements between 1000 and $1800 \mathrm{~K}$ and a review from 0 to $2000 \mathrm{~K}$. Geochemica et Cosmochimica Acta, 46, 2639-2658. https://doi.org/10.1016/0016-7037(84)90274-6

Rodgers, D., \& Little, T. (2006). World's largest coseismic strike-slip offset: The 1855 rupture of the Wairarapa Fault, New Zealand, and implications for displacement/length scaling of continental earthquakes. Journal of Geophysical Research, 111, B12408. https://doi.org/ 10.1029/2005JB004065

Rowe, C. D., Lamothe, K., Rempe, M., Andrews, M., Mitchell, T. M., Di Toro, G., et al. (2019). Earthquake lubrication and healing explained by amorphous nanosilica. Nature Communications, 10(1), 1-11. https://doi.org/10.1038/s41467-018-08238-y

Sagy, A., \& Brodsky, E. E. (2009). Geometric and rheological asperities in an exposed fault zone. Journal of Geophysical Research, 114, B02301. https://doi.org/10.1029/2008JB005701 
Shimamoto, T., \& Tsutsumi, A. (1994). A new rotary-shear high-speed friction testing machine: its basic design and scope of research (in Japanese with English abstract). Journal of the Tectonic Research Group of Jaapan, 39, 65-78.

Sibson, R. (1973). Interactions between temperature and pore-fluid pressure during earthquake faulting and a mechanism for partial or total stress relief. Nature Phyiscal Science, 243, 66-68. https://doi.org/10.1038/physci243066a0

Sibson, R. (2002). Geology of the crustal earthquake source. In S. W. Lee, P. Jennings, C. Kisslinger, \& H. Kanamori (Eds.), International handbook of earthquake \& engineering seismology (Vol. Part A, (pp. 455-473). London: Academic Press.

Siman-Tov, S., Aharonov, E., Sagy, A., \& Emmanuel, S. (2013). Nanograins from carbonate fault mirrors. Geology, 41(6), 703-706. https:// doi.org/10.1130/G34087.1

Simmons, J. H., Mohr, R. K., \& Montrose, C. J. (1982). Non-Newtonian viscous flow in glass. Journal of Applied Physics, 53(6), 4075-4080. https://doi.org/10.1063/1.331272

Sleep, N. H. (2019). Thermal Weakening of asperity tips on fault planes at high sliding velocities. Geochemistry, Geophysics, Geosystems, 20, 1164-1188. https://doi.org/10.1029/2018GC008062

Spray, J. G. (1987). Artificial generation of pseudotachylyte using friction welding apparatus: simulation of melting on a fault plane. Journal of Structural Geology, 9(1), 49-60. https://doi.org/10.1016/0191-8141(87)90043-5

Stesky, R. M., Brace, W. F., Riley, D. K., Robin, P.-Y., \& Robin, F. (1974). Friction in faulted rock at high temperature and pressure. Tectonophysics, 23(1-2), 177-203. https://doi.org/10.1016/0040-1951(74)90119-X

Tsutsumi, A., \& Shimamoto, T. (1997). High-velocity frictional properties of gabbro. Geophysical Research Letters, 41(6), 699-702. https:// doi.org/10.1029/97GL00503

Venkataraman, A., \& Kanamori, H. (2004). Observational constrainsts on the fracture energy of subduction zone earthquakes. Journal of Geophysical Research, 109, B05302. https://doi.org/10.1029/2003/JB002549

Webb, S. L., \& Dingwell, D. B. (1990). The onset of non-Newtonian rheology of silicate melts: A fiber elongation study. Physics and Chemistry of Minerals, 17(2), 125-132. https://doi.org/10.1007/BF00199663

Wibberley, C. A. J., \& Shimamoto, T. (2005). Earthquake slip weakening and asperities explained by thermal pressurization. Nature, 436 , 689-692. https://doi.org/10.1038/nature03901 